\title{
CLC, a promising concept with challenging development issues
}

Th.Gauthier ${ }^{\text {a }}$, M.Yazdanpanah ${ }^{\text {b }}$, A.Forret ${ }^{a}$, B.Amblard ${ }^{a}$, A. Lambert ${ }^{a}$ and S.Bertholin a IFP Energies nouvelles, BP3 69360 Solaize

${ }^{\mathrm{b}}$ Total, Research \& Technology Gonfreville (TRTG), 76700 Harfleur, France

Paper presented as a plenary lecture at the Fluidization XV conference,

Fairmont Le Chateau Montebello, Quebec, Canada (2016)

(http://dc.engconfintl.org/fluidization xv/)

Paper published in Powder Technology (2017)

Corresponding Author:

Th.Gauthier

IFP Energies nouvelles

BP 3 - 69360 Solaize France

Tel : (33)437.70.20.97

Email :thierry.gauthier@ifp.fr

Highlights:

- $\quad$ CLC is a very promising technique to reduce energy penalty for $\mathrm{CO} 2$ capture

- The concept is demonstrated at pilot scale

- Oxygen carrier stability needs to be improved

- Process technology is specific and scale-up addresses very large scale

- The CCS time to market delay is an opportunity for process optimization

Graphical abstract

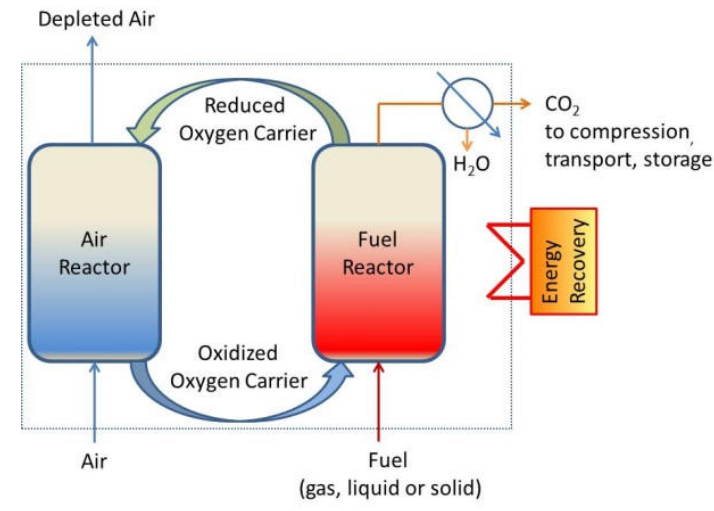

Key words : Chemical Looping Combustion, CO2 Capture and Storage, CCS, CLC, $\mathrm{CO} 2$ use, Oxygen carrier, Fluidized bed, Power plant, 


\section{Abstract}

Chemical Looping Combustion (CLC) is a promising technique to achieve fuel combustion in a nitrogen free atmosphere, therefore giving the possibility to separate and store or use $\mathrm{CO}_{2}$. Several potential applications are considered in the field of power generation with gas, liquid and mostly solid fuels. In the Carbon Capture, Storage and Utilization (CCSU) context, energy penalty is reduced with CLC compared to other routes. In addition, other applications of Chemical Looping Technology are considered in the field of $\mathrm{H}_{2}$ production or gasification for instance.

In the past years, a huge effort has been conducted worldwide to investigate CLC materials and process issues. In 2008, IFPEN and Total have started an ambitious collaboration to develop CLC applications. Nowadays, the CLC concept is well demonstrated on the pilot scale. The next step is to demonstrate the technology over time on a larger scale. For further developments, some challenges should be addressed, both on market and technical aspects:

- Short term market is limited. Uncertainties around $\mathrm{CO}_{2}$ emission market (i.e. carbon credits) and storage issues are hindering policy and public acceptance and still must evolve in the right direction,

- Financing of demonstration units for carbon capture in this context is challenging and other applications of CLC may require to be investigated such as utilization of captured CO2 for EOR purpose.

- The industrial use of synthetic metal oxides or natural ores at large scale generates a lot of issues related to availability, price, waste disposal, health and safety, additionally to chemical and mechanical aging, reactivity, and oxygen transfer capacity,

- Chemical looping reactor and process technology concepts have to be explored, developed, modeled and scaled-up in order to ensure adequate power production together with good gas solid contact and reaction requirement, controlled circulation of mixtures of particle (oxygen carrier, ash, solid fuel for instance). All these points should be considered on very large scales for carbon capture and storage (CCS) applications in order to minimize energy penalty and cost in severe operating conditions (temperatures above $800{ }^{\circ} \mathrm{C}$ and intense so lid circulation).

Technical challenges remain to be solved and proven with large demonstration over long periods of time. In this context, research in the field of fluidization technology is essential and we will address some key points investigated at IFPEN as related to control of solid circulation, oxygen carrier attrition, conceptual design of CLC reactors and process performance. 


\section{Introduction}

The reduction of $\mathrm{CO}_{2}$ emissions in the atmosphere to address global warming issues is one of the present challenges faced by society and particularly in the energy sector. $\mathrm{CO}_{2}$ capture and storage is one solution being considered. Over the last fifteen years, existing techniques such as post combustion separation or oxycombustion, have been adapted to capture $\mathrm{CO}_{2}$ in industrial flue gases. Today, many of these process technologies are considered as mature. However, the resulting energy penalty induced is quite high. For the same net amount of energy produced, these processes will use up to $15-25 \%$ more fuel depending upon the technology. Therefore, worldwide, a lot of efforts are conducted to reduce the energy penalty, either by improving these existing concepts or by developing new processes, such as Chemical Looping Combustion (CLC). In CLC, oxygen carriers are used to transfer oxygen through redox cycles and circulation between an oxidizing zone and a reducing zone where the fuel is burnt in a nitrogen free atmosphere (Fig.1). Nitrogen free $\mathrm{CO}_{2}$ can be recovered from the fuel reactor effluents. Compared to Oxycombustion, intrinsic oxygen separation is therefore conducted and no energy penalty is induced by gas separation. Fluidized bed is generally considered as the technology for CLC due to the apparent ease to circulate particles between the air reactor and the fuel reactor.

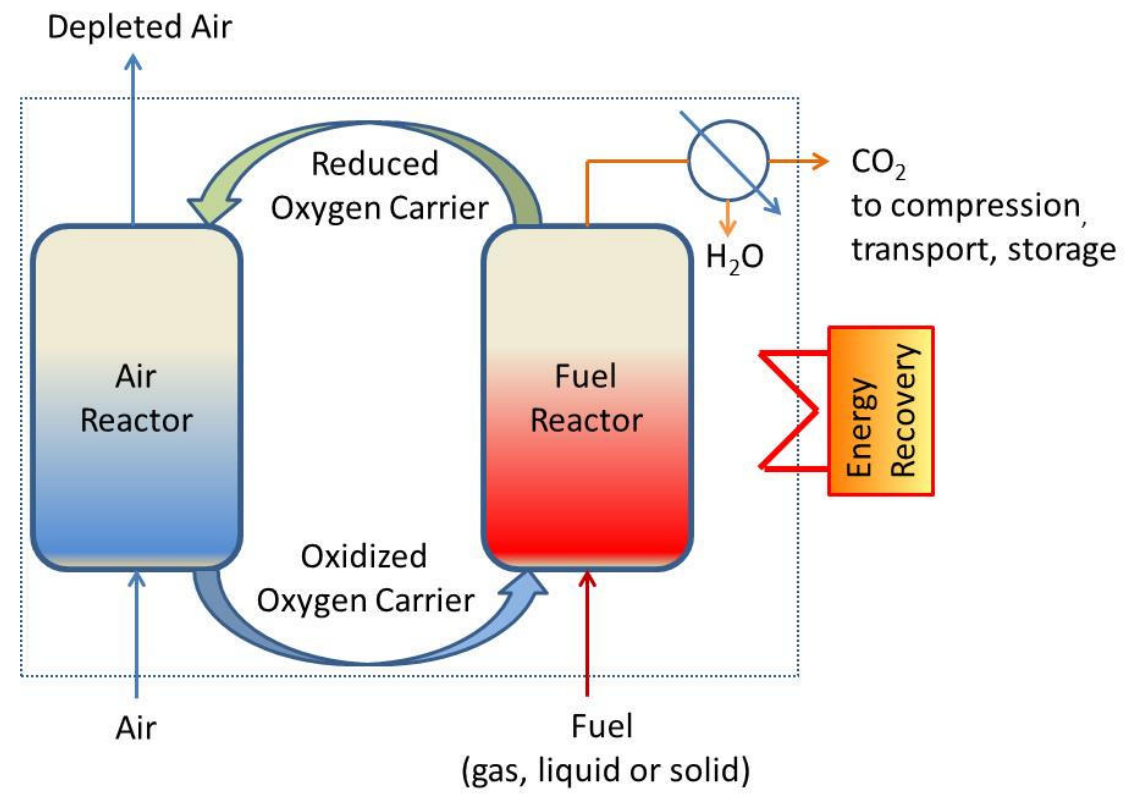

Figure 1: the CLC concept

Primarily, CLC applications relate to energy and power plants using fossil fuel combustion with $\mathrm{CO}_{2}$ capture. However, $\mathrm{CO}_{2}$ capture and storage short term market is presently limited due to uncertainties around $\mathrm{CO}_{2}$ market policies and public acceptance of storage. In the Oil and Gas industry, more specific applications are also considered, such as $\mathrm{CO}_{2}$ production to Enhance Oil Recovery (EOR) or to produce steam for extra heavy oil extraction (SAGD). The Chemical Looping concept can also be derived for other applications, such as gasification, maleic anhydride and hydrogen production...

Total and IFPEN started a joined R\&D program in 2008 to develop novel CLC process technologies with $\mathrm{CO} 2$ capture and storage incentives in mind. The objective was, first, to build relevant tools and conduct research in order to develop a clear and complete understanding of the process constraints and to estimate achievable performances and associated costs at industrial scale. After which, the development and commercialization of the process.

In the first part of this paper, we will review the $\mathrm{CO}_{2}$ capture, storage and utilization market situation, some of the $\mathrm{CO}_{2}$ capture technologies available, discuss the maturity and compare the $\mathrm{CO}_{2}$ avoidance cost and energy penalty of these technologies. In the second part of the paper, we 
will discuss CLC development status by addressing the potential applications considered, oxygen carriers use and R\&D tools available. In the third part of the paper, we will highlight some of the technical challenges related to fluidized bed technology use in the CLC process already investigated by Total and IFPEN related to the control of solid circulation, oxygen carrier attrition, conceptual design of CLC reactors and process performances.

\section{2. $\mathrm{CO}_{2}$ Capture, Storage and Use (CCSU)}

According to IEA [1] , global $\mathrm{CO}_{2}$ emissions resulting from fossil fuel combustion represented about $32 \mathrm{Gt} / \mathrm{y}$ in 2013 with more than $46 \%$ resulting from coal combustion. $\mathrm{CO}_{2}$ emissions for heat and electricity generation by coal combustion represent about $10 \mathrm{Gt} / \mathrm{y}$ of $\mathrm{CO}_{2}$ (which is about twice the amount of 1990 emissions) emitted every year. This huge amount can be considered as a waste, either accumulating in the atmosphere $\left(\mathrm{CO}_{2}\right.$ concentration is presently in the range of 400 ppm), either captured and stored somewhere else, either captured and used. Global warming mitigation requires to limit accumulation of $\mathrm{CO}_{2}$ in the atmosphere. IEA [2] suggests the need for capturing over $7 \mathrm{Gt} / \mathrm{y}$ of $\mathrm{CO}_{2}$ by 2050 in order to meet the $2^{\circ} \mathrm{C}$ target scenario. In order to achieve this objective, we probably need to focus on large emitters and several plants will be needed to capture $\mathrm{CO}_{2}$. As an example, a large $500 \mathrm{MW}_{\text {th }}$ coal power plant that produces $200 \mathrm{MW}_{\mathrm{e}}$ typically emits $1.1 \mathrm{Mt} \mathrm{CO}_{2} /$ year and could possibly produce $\mathrm{CO}_{2}$ concentrated flue gas stream in the range of $1 \mathrm{Mt} / \mathrm{year}$, assuming a capture efficiency in the range of $90 \%$.

\subsection{CCSU status}

At present, according to the Global CCS Institute [3], 15 large-scale CCS projects are in operation around the world with a global capture capacity in the range of $28 \mathrm{Mt} / \mathrm{y}$ of $\mathrm{CO}_{2}$. There are 7 more CCS projects in the Execute Stage, that should allow to achieve a capture capacity of $40 \mathrm{Mt} / \mathrm{y}$ in 2017. Furthermore,11 other projects are in Define Stage and represent an additional capture capacity of around $15 \mathrm{Mt} / \mathrm{y}$ (see Fig.2). Considering further new projects in the early stages of planning, the most optimistic predictions give a total $\mathrm{CO}_{2}$ capture capacity of $80 \mathrm{Mt} / \mathrm{y}$ of $\mathrm{CO}_{2}$ by 2020 , which is only about $1 \%$ of the IEA's $7 \mathrm{Gt} \mathrm{CO}_{2} / \mathrm{y}$ estimate to achieve the ${ }^{2} \mathrm{C}$ target scenario in 2050 [2]. Therefore, the CCS market should grow exponentially in the next decades. It also means that, the storage (or use) of $\mathrm{CO}_{2}$ in huge amounts is a pre-requisite for considering CCS as a key lever of the energy policy to reduce GHG emissions.

\section{Large scale CCS projects around the world}

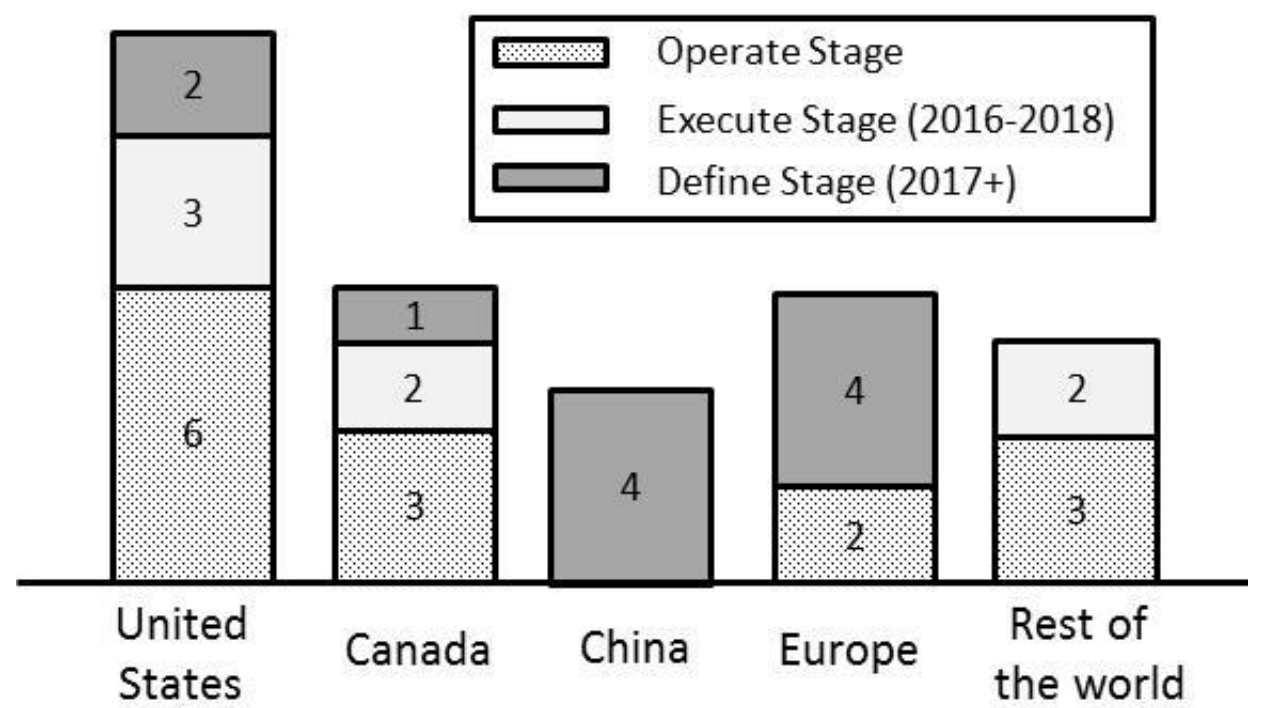

Figure 2: Actual and expected operation dates for large-scale CCS projects [3] 


\section{$2.2 \mathrm{CO}_{2}$ storage}

$\mathrm{CO}_{2}$ storage is usually considered in 3 main geological media [4] :

1. Deep saline aquifers made of porous and permeable rocks saturated with salt water and brines. These formations are present worldwide, both offshore and onshore, and have the largest $\mathrm{CO}_{2}$ storage capacity of all geological formations,

2. Oil and gas reservoirs, especially where Enhanced Oil Recovery (EOR) can be implemented. In this case, $\mathrm{CO}_{2}$ is injected into the well at a pressure level such that $\mathrm{CO}_{2}$ and crude oil are miscible. In this way, the viscosity of oil is reduced and the $\mathrm{CO}_{2}$ pressure ensures the driving force for the extraction. Up to $40 \%$ of the residual oil left after a primary production can be extracted with this method and a large amount of $\mathrm{CO}_{2}$ can be stored permanently,

3. Deep coal unmineable beds, especially where methane is trapped into the porous structure. As for EOR, injection of $\mathrm{CO}_{2}$ could simultaneously enhance the recovery of methane and ensure the $\mathrm{CO}_{2}$ sequestration. However, previous studies have shown that the potential of this kind of storage is limited due to leakage risks and limited available storage capacities.

Deep ocean storage concepts have also been investigated by dissolving $\mathrm{CO}_{2}$ into the water, possibly below $1,000 \mathrm{~m}$ depth, or preferentially below $3,000 \mathrm{~m}$ depth where $\mathrm{CO}_{2}$ will be liquefied and sunk to the bottom due to its higher density than the seawater. The potential is great, but in both cases, the addition of $\mathrm{CO}_{2}$ in the ocean will affect the seawater acidity (by reducing the $\mathrm{pH}$ ) and impact on the marine ecosystem. More studies are required to assess the environmental risk before considering this storage. This route is not considered anymore except in Japan.

The criteria to be considered for the assessment of storage capacity are well-known and relate to technical, economic and regulatory issues. Technically, a combination of physical and chemical trapping mechanisms and characteristics need to be considered at different timeframes to estimate storage capacities [5]. The costs for geological storage depend on reservoir type and geology. The literature provides a wide range of costs which may vary from 1 to $18\left(2013 \$ / \mathrm{tCO}_{2}\right)$ [6]. More specifically, for EOR applications, due to potential oil production benefits, $\mathrm{CO}_{2}$ storage has an economic viability that relates to the cost of available $\mathrm{CO}_{2}$ compared to the oil price: at $100 \$ / \mathrm{bbl}$ oil price, an acceptable $\mathrm{CO}_{2}$ cost should be in the range of $40 \$ / \mathrm{tCO}_{2}$. The driving force for developing $\mathrm{CO}_{2}$ storage through EOR business is therefore the oil price. From a regulation point of view, public safety and environmental protection is the priority. Several studies have been conducted to assess the risk of $\mathrm{CO}_{2}$ leakage [4]. The leakage through cap rock will be very slow but other risks for surrounding environment, such as groundwater and soil acidification need to be evaluated. On the contrary, leakage through permeable pathway, especially close to the injection well, can evolve faster and become harmful for health. In any case, proving appropriate storage capacity requires several years and long-term monitoring must be carried out to ensure sealing of the storage during several thousand years.

Based on these criteria, the prospects for storage of $\mathrm{CO}_{2}$ are mixed at the present time. On one hand, all detailed regional surveys of storage resources that were conducted in most developed countries have shown that available storage capacities exceed the storage needs. For instance, the US DOE indicates that $1.600 \mathrm{Gt}$ of $\mathrm{CO}_{2}$ could be stored in the US, representing more than 250 years of current $\mathrm{CO}_{2}$ emissions in the US [3]. In Europe, the EU GeoCapacity project [7] estimated a total European storage capacity of $126 \mathrm{Gt}$, to be compared with the $2 \mathrm{Gt} / \mathrm{y}$ total emissions resulting from large stationary source. From a technical point of view, storage of $\mathrm{CO}_{2}$ is, thus, a suitable solution. On the other hand, market incentives and long-term environmental policies are yet not sufficient for creating a positive business case for CCS. Last but not the least, several social science studies [8] show that public perception of CCS is mainly focused on the risks linked to the transport and storage of $\mathrm{CO}_{2}$. To obtain adhesion and general public acceptance, we need the recognition that global climate change is a serious problem and that a reduction of $\mathrm{CO}_{2}$ emissions is needed [9]. Unfortunately, awareness seems still insufficient at this time. 


\section{$2.3 \underline{\mathrm{CO}}_{2}$ use}

If $\mathrm{CO}_{2}$ is not stored when captured, an opportunity could be to consider $\mathrm{CO}_{2}$ as a feedstock for other applications. Indeed, there are many potential uses of $\mathrm{CO}_{2}$ [10] as shown in Fig.3. As stated before, without reacting, $\mathrm{CO}_{2}$ can be used in the Oil and Gas industry for Enhanced Oil Recovery (EOR), but also as a solvent in supercritical conditions, as a working fluid in refrigeration cycles or in the food industry. Considering chemical reaction, there are several opportunities to use $\mathrm{CO}_{2}$ as a reactant in organic synthesis, mineralization and carbonate formation, hydrogenation, dry reforming, electrolysis, photocatalysis and thermochemistry. $\mathrm{CO}_{2}$ is already used as a chemical feedstock for urea and polycarbonates synthesis and is seriously considered for methane, methanol synthesis and fuel production [10]. It can also be used as a feedstock for biological transformation, to produce microalgae or in biocatalytic processes.

\section{Potential $\mathrm{CO}_{2}$ Use}

\begin{tabular}{|c|c|c|}
\hline $\begin{array}{l}\text { Without reaction } \\
\text {-EOR } \\
\text {-Supercritical } \mathrm{CO}_{2} \\
\text {-Other } \mathrm{CO}_{2} \text { industrial } \\
\text { uses }\end{array}$ & $\begin{array}{l}\text { With chemical reaction } \\
\text { Organic synthesis } \\
\text { Urea } \\
\text { Carbonates and polycarbonates } \\
\text { Carbamates and polycarbamates } \\
\text { Carboxylic acids, .... }\end{array}$ & $\begin{array}{l}\text { With biological reactions } \\
\text {-Microalgae } \\
\text {-Biocatalytic processes } \\
\text {-... }\end{array}$ \\
\hline & $\begin{array}{l}\text { My arogenation } \\
\mathrm{CH}_{4}, \mathrm{CH}_{3} \mathrm{OH}, \mathrm{HCOOH}, \mathrm{O}(\mathrm{RWGS}) \ldots \\
\text { Mineralization } \\
\text { Carbonates, } \ldots \\
\text { Dry reforming }\left(\mathrm{CH}_{4}+\mathrm{CO}_{2}\right) \\
\text { Syngas } \\
\text { Electrolysis }\left(\mathrm{CO}_{2}+\mathrm{H}_{2} \mathrm{O}\right) \\
\text { Syngas } \\
\mathrm{CH}_{3} \mathrm{OH}, \mathrm{CH}_{4}, \mathrm{CHCO}, \mathrm{HCOOH}, \ldots \\
\text { Photocatalysis }\left(\mathrm{H}_{2} \mathrm{O}+\mathrm{CO}_{2}\right) \\
\mathrm{H}_{2}, \mathrm{CO}, \mathrm{CH}_{4}, \mathrm{HCOOH}, \mathrm{CHCO}, \ldots \\
\text { Thermochemistry }\left(\mathrm{H}_{2} \mathrm{O}+\mathrm{CO}_{2}\right) \\
\text { CO, } \mathrm{H}_{2,} \text { syngas,... }\end{array}$ & \\
\hline
\end{tabular}

Figure 3: The different routes considered for $\mathrm{CO}_{2}$ upgrading

However, at present, the amount of $\mathrm{CO}_{2}$ used as a resource for $\mathrm{CO}_{2}$ upgrading processes remains limited (in the range of $200 \mathrm{Mt}$ ), due to several difficulties explaining why $\mathrm{CO}_{2}$ use cannot be considered yet as a global solution for global warming mitigation:

- The $\mathrm{CO}_{2}$ molecule is extremely stable. A lot of energy is needed, either directly or indirectly (through a reducing agent such as $\mathrm{H}_{2}$ ) for $\mathrm{CO}_{2}$ conversion. In each specific case, apart from economic benefits, the energy balance and environmental impact have therefore to be evaluated carefully.

- In general, the market of products resulting from $\mathrm{CO}_{2}$ conversion is rather small compared to $\mathrm{CO}_{2}$ emissions. As an example, the methanol market worldwide is in the range of $65 \mathrm{Mt} / \mathrm{y}$ representing about $0.2 \%$ of the $\mathrm{CO}_{2}$ emissions. The formic acid market is much smaller, in the range of $0.7 \mathrm{Mt} / \mathrm{y}$.

- Valuable concentrated $\mathrm{CO}_{2}$ sources are limited yet and expensive capture and purification processes have to be implemented upstream of the $\mathrm{CO}_{2}$ reaction process.

Additionally, for most applications, the $\mathrm{CO}_{2}$ storage time period depending on product lifetime is in most case shorter than a year. As a consequence, fossil carbon use may be avoided but $\mathrm{CO}_{2}$ concentration in the atmosphere will not decrease significantly if $\mathrm{CO}_{2}$ use increases.

The Power to Gas Concept, taken as an example, illustrates some of the issues related to $\mathrm{CO}_{2}$ use. Power to Gas is a new area of research and innovation in Europe [11]. This concept was originally developed in Germany to convert excess renewable electricity into methane. $\mathrm{CO}_{2}$ (usually coming from biogas plants) is converted to methane while using hydrogen produced by 
water electrolysis. However, due to the lower price of natural gas compared to electricity, $\mathrm{CH}_{4}$ produced by methanation is much more expensive than natural gas. Furthermore, the energy yield is not very high compared to existing alternative electricity storage solutions. In the end, even if all the $\mathrm{CO}_{2}$ produced nowadays by German biogas plants (the largest biogas producing country) was converted into methane, this would correspond to roughly $10 \mathrm{Mt} \mathrm{CO}_{2}$ converted per year, about $1 \%$ of the present German $\mathrm{CO}_{2}$ emissions. In Germany, there are presently other possible justifications to power to gas (the electricity network is more limited than the gas network..) but, clearly, the economical challenge is huge and the potential impact on $\mathrm{CO}_{2}$ emissions remains limited.

Among the different routes available to upgrade $\mathrm{CO}_{2}$ (see Fig.3), mineralization may adress large markets in the range of $100 \mathrm{kt}$ to $1 \mathrm{Gt} \mathrm{CO}_{2}$ and sequestration periods in tens of years [10]. However, in most cases, since $\mathrm{CO}_{2}$ is a very stable molecule, the energy needed to achieve $\mathrm{CO}_{2}$ transformation is high and the product's added value is small. Therefore economics is challenging. Fuel markets may adress still larger volumes $\left(2-3 \mathrm{Gt} \mathrm{CO}_{2}\right)$, but the development status is still very preliminary and the economical challenge is also huge in this case.

\subsection{CCS techniques and capture cost}

$\mathrm{CO}_{2}$ capture processes can be divided into three categories: pre-combustion, oxy-fuel combustion, and post combustion. To date, most of the industrial CCS operations are performed using gas treating technologies such as amine solvent, adsorption or distillation, preferentially in precombustion for the major plants in terms of capacity (Century Plant, Shute Creek, Great Plains, etc.) or in post-combustion in the case of Power Plant retrofit (Boundary Dam, Brindisi, Tampa, etc.). Oxy-combustion is less developed nowadays and still requires a first reference at large scale such as FuturGen 2.0 and White Rose in England.

Pre-combustion systems normally involve a first step of converting the fuel into hydrogen and $\mathrm{CO}_{2}$ via reforming and shift reactions. Carbon dioxide is then captured and stored. Finally, hydrogen, as a carbon free fuel is burnt with air. The $\mathrm{CO}_{2}$ separation step is claimed to be easier compared to post combustion systems thanks to the fact that the flue gas is more concentrated and at higher pressure in this case.

Oxy-fuel combustion consists in the use of pure oxygen instead of air. In this technology, a portion of the flue gas is recirculated back into the combustion chamber to control the flame temperature in the absence of nitrogen [12]. TOTAL has tested gas feed oxy-fuel combustion in a $30 \mathrm{MW}_{\text {th }}$ pilot in Lacq, France combined with $\mathrm{CO}_{2}$ transportation and underground storage [13]. Coal oxy-fuel combustion was also studied and demonstrated at large scale: Vattenfall operated a $30 \mathrm{MW}_{\text {th }}$ coal oxy-fuel power plant demo in Schwarze Pumpe (Germany). At present, large industrial projects such as the White Rose project in England (FEED stage) have been very seriously considered, but have then been cancelled due to financing issues in the present $\mathrm{CO}_{2}$ market context. Air separation cost and energy penalty, combustion flame temperature control, corrosion in the recirculation line, and $\mathrm{CO}_{2}$ purification are some of the existing challenges related to this technology.

Post combustion capture includes a large number of technologies such as chemical solvent absorption, solid adsorption, membrane separation, cryogenic separation, and pressure swing adsorption [14]. Mono-Ethanol Amine (MEA) based absorption technology is presently the most developed system, already used industrially for several applications such as sour gas washing. This technology is considered as a reference case for $\mathrm{CO}_{2}$ capture regarding to its maturity. However, there is a high additional energy penalty in the electricity yield for $\mathrm{CO}_{2}$ capture of about $10 \%$ [15] and amine make-up is significant due to high oxidative degradation of the MEA Solvent. Some breakthrough solvents alternative to MEA are now proposed to reduce the energy penalty and solvent degradation, such as the $\mathrm{DMX}^{\mathrm{TM}}$ process developed by IFPEN using a phase change solvent to reduce $\mathrm{CO}_{2}$ capture cost [16].

Abanades et al. [17] recently reviewed alternative emerging $\mathrm{CO}_{2}$ capture technologies using adsorbent, membranes and Chemical Looping. Among these solutions, CLC is commonly 
considered as a second generation of oxy-fuel combustion where an oxygen carrier is used to transfer oxygen to fuel. The intrinsic $\mathrm{O}_{2}$ separation resulting from the combination of the oxygen carrier circulation and the split of combustion into two combined sections permits to produce $\mathrm{CO}_{2}$ streams without air separation unit. Therefore, the energy penalty can potentially be greatly reduced. Industrial process simulation by Authier and Le Moullec [18] shows that CLC can attain a net electrical efficiency of up to $41.6 \%$ compared to $45 \%$ for a CFB unit without $\mathrm{CO}_{2}$ capture with a high pressure steam of 280 bar at $600{ }^{\circ} \mathrm{C}$. Most of the energy penalty relates to $\mathrm{CO}_{2}$ compression. Similar conclusions were obtained in the Encap European project 5 years ago [19]. A simplified techno-economic evaluation was carried out to study CO2 capture and compression up to 110 bar. Several capture technologies were evaluated including a $455 \mathrm{MW}_{\mathrm{e}}$ CLC with coal feed. CLC estimates were favorable with a limited $20 \%$ additional electricity cost and a very low $\mathrm{CO}_{2}$ capture cost estimated in the range of about $10 € /$ ton of $\mathrm{CO}_{2}$ (2004); a $42 \%$ electrical efficiency was estimated with CLC, to be compared with the $45 \%$ electrical efficiency obtained for the reference case with coal feed.

In the frame of the IFPEN-Total collaboration for CLC development, we conducted recently a detailed techno-economic study in order to compare several CCS technologies using a reference coal power plant project of $630 \mathrm{MW}_{\mathrm{e}}$, with the same economical basis (France, 2012). A large part of the supply costs for CLC were estimated through suppliers. Natural ore with a supply cost of $1 € / \mathrm{kg}$ was considered, and the unit inventory was supposed to be renewed three times a year due to aging. We studied the impact of the $\mathrm{CO}_{2}$ capture process on $\mathrm{CO}_{2}$ avoidance cost and energy efficiency. In Table 1 below, the CLC estimates and the results obtained with a standard post combustion process using 30\% MEA Amine washing process are compared to the reference case. The energy penalty related to $\mathrm{CO}_{2}$ capture with $\mathrm{CLC}$ is estimated to $4.9 \%$. More than $80 \%$ of this energy penalty corresponds to the $\mathrm{CO}_{2}$ compression cost for transportation. In the same conditions but with conventional post-combustion amine processes (or with oxycombustion processes), the overall energy penalty including $\mathrm{CO}_{2}$ compression cost is about twice the energy penalty of CLC. In this study, we could estimate $\mathrm{CO}_{2}$ avoidance cost for CLC in the range of $37 € / \mathrm{t}$, to be compared with the costs obtained with amine (and oxycombustion processes) in the range of 50-60€/t. With CLC, the overall investment cost would be increased by $50 \%$ compared to $70 \%$ with standard amine solutions.

\begin{tabular}{|c|c|c|c|c|}
\cline { 2 - 5 } \multicolumn{1}{c|}{} & Power & $\begin{array}{c}\text { Net } \\
\text { Electric } \\
\text { Yield }\end{array}$ & $\begin{array}{c}\text { Electricity } \\
\text { production } \\
\text { cost }\end{array}$ & $\begin{array}{c}\text { CO2 } \\
\text { avoidance } \\
\text { cost }\end{array}$ \\
\cline { 2 - 5 } \multicolumn{1}{c|}{} & $($ Mwe) & $(\%)$ & $(€ /$ Mwhe) & $€ /$ CO2 \\
\hline Reference & 630 & 44.9 & 63 & \\
\hline CLC & 630 & 40.0 & 88 & 37 \\
\hline Amine 30\% MEA & 630 & 34.9 & 98 & 53 \\
\hline
\end{tabular}

Table 1 : Impact of $\mathrm{CO}_{2}$ capture on electric yield and production cost

Clearly, amine and oxycombustion process developments are much more advanced, with existing large scale demos and plants in operation, while CLC is still at the development stage. This study, however, points out the promising potential of CLC with expected reduced energy penalty and lower $\mathrm{CO}_{2}$ avoidance costs. One has to keep in mind, however, that, whatever the process considered, $\mathrm{CO}_{2}$ avoidance cost is and will remain significant. This results from additional investments required to capture $\mathrm{CO}_{2}$ (in large power plants, this corresponds to hundreds of millions of dollars) and additional operating costs. From an industrial perspective, this charge can only be justified by a $\mathrm{CO}_{2}$ market value and incentive policies.

\subsection{CO2 market}

Implementation of $\mathrm{CO}_{2}$ capture is an additional cost for the main industrial $\mathrm{CO}_{2}$ emitters (Power industry, Refineries, Cement and Steel industries) that needs to be justified by $\mathrm{CO}_{2}$ market value 
and incentive policies. A recent benchmark study conducted by IPCC [6] provides an update of CCS costs based on a literature review. They conclude that carbon prices in the range of $\$ 50$ $100 / \mathrm{tCO}_{2}$ are required to make CCS attractive $(80-90 \%$ of this value is justified by capture). These values could be positively reduced with new capture processes such as CLC or by giving a value to $\mathrm{CO}_{2}$, depending on $\mathrm{CO}_{2}$ use (for instance up to $\$ 10-60 / \mathrm{tCO} 2$ considering $\mathrm{EOR}$ credits depending on price of oil as discussed earlier).

In order to motivate huge investments required for $\mathrm{CO}_{2}$ capture, it is necessary to develop structured $\mathrm{CO}_{2}$ markets. On this point, even if climate warming is a worldwide issue with global consensus requirements (e.g. COP21 in Paris), the deployment of CCS should probably be investigated on a regional scale to integrate the specificities of each area in terms of economy (developed or developing countries), type of energy available (coal, oil, gas) and environmental constraints. Indeed, the six largest $\mathrm{CO}_{2}$ emitters representing about $70 \%$ of global emissions [20] are implementing different strategies to tackle the issue :

- China is the first $\mathrm{CO}_{2}$ emitter worldwide (almost $10 \mathrm{Gt}$ in 2014) and should continue to increase its emissions for at least another 10 years. As a result, China intends to demonstrate strong policy support for CCS and plans to implement a national emissions trading scheme from 2016 with the goal to achieve the peak of emission in 2030 at the latest.

- The United States is the first $\mathrm{CO}_{2}$ emitter for developed countries and is ranked second in the world with nearly $6 \mathrm{Gt}$ of $\mathrm{CO}_{2}$ emission in 2014 [21]. The political will was recently reaffirmed through the common US-China declaration to reduce emissions by $28 \%$ in 2025 . A recent study from Synapse Energy Economics [22] forecasts a generalization of $\mathrm{CO}_{2}$ market in the US in 2020 and an increase of $\mathrm{CO}_{2}$ price to $\$ 25-54 / \mathrm{tCO}_{2}$ in 2030 and to $\$ 45$ 120/tCO2 in 2050 (expressed in 2014 dollars).

- The European Union has created the first Emissions Trading System in 2005 but the economic downturn didn't allow the deployment of the market. The EU has a common goal of reducing the emissions by $40 \%$ (based on 1990 emission rate) by 2030, and has launched the large funding program NER300 to support demonstration of new technologies at commercial scale.

- Russia and India are each ranked in the top five but policy incentives are still at a low level in these countries [5]. They focused on other means to achieve their goal of decreasing $\mathrm{CO}_{2}$ emissions and do not strongly support research for CCS technology.

- Japan has to face with an increase of its $\mathrm{CO}_{2}$ emissions since the government decided to replace the nuclear energy by natural gas and coal after the Fukushima disaster. The goal of reducing emissions by $26 \%$ (based on 2013 emissions) by 2030 should create opportunities for CCS.

To date, pricing mechanisms have been launched in most of the major emitting countries (UE, US, China, Japan, Australia, Mexico, South Korea, Canada, etc.). There is progress, as shown in Table 2 below, but these regional pricing mechanisms still cover less than $12 \%$ of worldwide emissions.

\begin{tabular}{|c|l|c|}
\cline { 3 - 3 } \multicolumn{2}{c|}{} & $\begin{array}{c}\text { part of emissions } \\
\text { covered by pricing } \\
\text { mechanism }\end{array}$ \\
\hline $1990-2004$ & first carbon tax in Nordic countries and poland & $0.30 \%$ \\
\hline $2005-2011$ & EU emission trading system & $4 \%$ \\
\hline 2012 & carbon market in California, carbon Tax in Japan & $7.40 \%$ \\
\hline 2013 & Regional carbon marketslaunched in China & $9.60 \%$ \\
\hline 2016 & present situation & $12.30 \%$ \\
\hline
\end{tabular}

Table 2: Part of global emissions covered by national or regional pricing mechanisms 
Over the last years and still presently in 2016, $\mathrm{CO}_{2}$ policies remain limited and resulting $\mathrm{CO}_{2}$ prices are still very low, as shown in Fig.4. However, a positive outlook has emerged from the recent COP 21 since the part of the worldwide emissions that will be covered by $\mathrm{CO}_{2}$ policies is expected to range up to $85 \%$ of global emissions in a near future. Therefore, all the commitments made by the governments should result in a driving force for developing CCS resulting in higher $\mathrm{CO}_{2}$ prices. At present, a progressive increase is expected, both in Europe and in North America, as shown in Fig.4. This suggests that $\mathrm{CO}_{2}$ prices may be in the range of $30-35 € / t$ in 2030 , which is in the range or below present $\mathrm{CO}_{2}$ avoidance cost estimates. Based on this trend, over the last years, most of the development roadmaps for CCS have been delayed by roughly ten years, from 2015-2020 to 2025-2030 compared to the ambitious plans that were considered before 2010 .

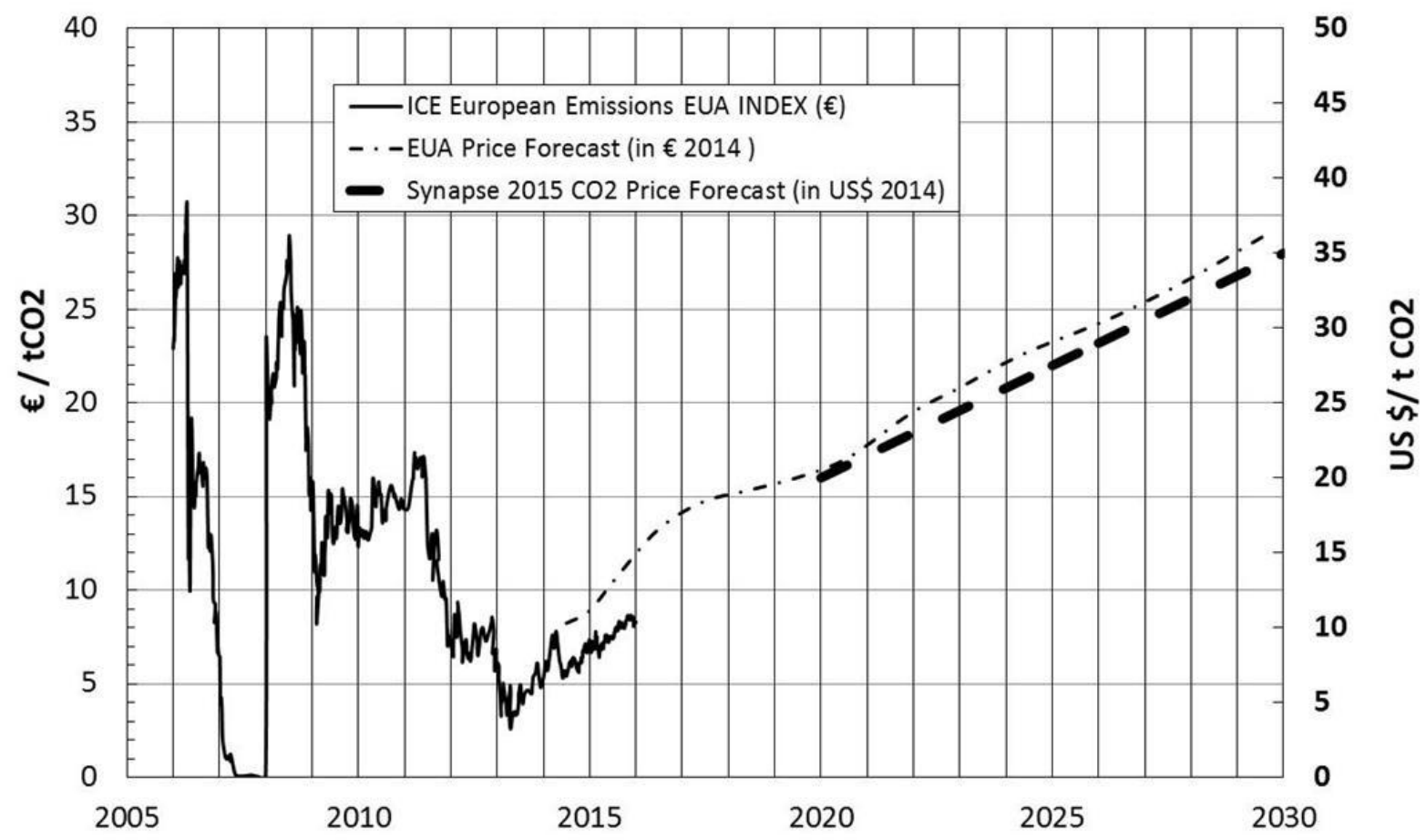

Figure $4: \mathrm{CO}_{2}$ price in Europe over the 2006-2015 period and projections to 2030 in Europe and in the US

\section{CLC Development status}

\subsection{CLC applications}

Chemical Looping has gained a lot of interest after Ishida et al. [23] proposed the use of CLC as a mean to capture $\mathrm{CO}_{2}$. Ishida et al. [24] proposed the term Chemical Looping to describe a high exergy efficiency combustion process using metal oxides as reaction intermediates. As pointed out by Fan et al. [25], several researchers had already considered the use of metal oxides as intermediates to conduct several redox reactions to produce either hydrogen, $\mathrm{CO}_{2}$ or syngas early in the $20^{\text {th }}$ Century. More recently in the $80 \mathrm{~s}$, an important R\&D work was dedicated to the production of ethylene and ethane (oxidative coupling of methane) as well as maleic anhydride [25] using metal oxides. With the increasing concern of global warming in the 90's, the reduction of $\mathrm{CO}_{2}$ emissions in the atmosphere through carbon capture and storage has motivated a lot of new 
investigations, including Chemical Looping, which became a promising concept motivating important R\&D effort. Over the last five years, the number of records addressing Chemical Looping in the Web of Science database dramatically increased and is in the range of 200 scientific publications per year. A new International Conference is now dedicated to CLC since 2010 and happens every 2 years (2010 at IFP Energies nouvelles in Lyon, France; 2012 at TU Darmstadt in Germany; 2014 at Chalmers University in Sweden; 2016 at Southweast University in Nanjing, China). Most of the research in Chemical Looping using metal oxides as oxygen carriers clearly focused on hydrocarbon combustion for $\mathrm{CO}_{2}$ Capture and Sequestration (CCS) and reforming technologies, as discussed by Adanez et al. [26]. The Chemical Looping concept can also be extended to $\mathrm{CO}_{2}$ capture in post combustion flue gases using adsorbents [27].

Over the last years, a considerable amount of work has been conducted on CLC, covering almost all kinds of hydrocarbon feedstocks. Researches were initiated by methane combustion studies and focused on oxygen carrier screening, small scale batch reactors and pilot plants, with the first trials in the GRACE project at Chalmers [28]. Based on this work, research rapidly extended in several places [29-32]. However, since most of the CCS concerns relate to coal combustion, the experimental tools were also progressively adapted in order to study and develop coal or pet coke combustion, either through in situ gasification and further combustion of syngas [33-36] (solid fuelled CLC), coal gasification followed by syngas Chemical Looping Combustion [37-38] (syngas CLC) or Chemical Looping Uncoupling (CLOU) process [39] where the solid fuel is burnt with gaseous oxygen released in the fuel reactor by the oxygen carrier [26]. Liquid fuel combustion was also investigated [40-41]. Alternative resources such as biomass and wastes have also been considered, with further GES accounts benefits. Indeed, in the early stages of investigations for solid fuel combustion, plastic waste and wood combustion were also studied at small scale [42], and soon extended at pilot scale [43]. Despite the Chemical Looping Combustion principle being simple, oxygen carriers, operating conditions and technologies have to be optimized depending upon the nature of the hydrocarbon feedstock [26]. Therefore, specific research and development is required depending upon the specific application considered.

For combustion applications, the pressure should be kept as low as possible in order to minimize energy compression cost. The combustion temperature relates to the kind of feedstock and oxygen carrier used. Very high temperature in the range of $850-950^{\circ} \mathrm{C}$ may have to be considered in the fuel reactor operating with solid fuels [36], resulting in higher temperatures in the air reactor as a function of heat balance requirements.

The other main field of investigation for Chemical Looping studies relates to Chemical Looping Reforming for hydrogen production. Indeed, hydrogen production through standard steam methane reforming generates also large amounts of $\mathrm{CO}_{2}$ diluted in $\mathrm{N}_{2}$. Therefore, several teams started to focus on the integration of $\mathrm{CO}_{2}$ capture processes with the $\mathrm{H}_{2}$ production process using Chemical Looping concept [25, 44-45]. Alternatively, $\mathrm{H}_{2}$ can also be produced from syngas from coal gasification using Chemical Looping concept as proposed by Fan [46]: syngas is first used to reduce metal oxide that is then oxidized with steam in a distinct reactor to produce pure hydrogen. In order to minimize energy compression cost, a Chemical Looping Reforming process should probably be operated at high pressure. This needs to be accounted for when considering reactor technologies and high pressure operation may create additional scale-up issues with interconnected fluidized bed reactors.

\subsection{Oxygen carrying materials}

A large number of oxygen carriers have already been considered and tested for Chemical Looping applications [26]. Two main oxygen carrier categories can be distinguished : synthetic particles and natural ores. The oxygen transfer capacity and reactivity of the oxygen carriers depend on the nature and amount of active phase in the particles, as well as on the possible interaction with the ceramic support. As a rule of thumb, $\mathrm{Ni}$ and $\mathrm{Cu}$ based particles are the most reactive, but their cost 
is higher than Fe or Mn based oxygen carriers and toxicity is a major concern with Ni particles. Thermodynamic limitations as well as toxicity and cost make Co based particles uninteresting.

Most of the studies relate to synthetic particles, since it is possible to tune their reactivity, oxygen transfer capacity and mechanical resistance. They are generally composed of an active phase (a metal oxide of $\mathrm{Mn}, \mathrm{Fe}, \mathrm{Co}, \mathrm{Ni}$ and $\mathrm{Cu}$, or a mixture thereof) mixed with a ceramic binder or support (typically alumina, silica, yttria, clays...) which prevents the fast deactivation observed with pure metal oxides and improves their mechanical stability (i.e. attrition). The preparation of synthetic particles has mainly been performed either by impregnation of the active phase on a support with adequate particle size distribution, or by spray drying of a suspension containing the required starting materials [26]. High temperature calcination is then usually applied to the particles in order to enhance their mechanical resistance. While producing spherical particles in the $50-100 \mu \mathrm{m}$ range (for the FCC process) is easily achievable at industrial scale by spray-drying, increasing the particle size to the $100-300 \mu \mathrm{m}$ range that is often required to meet the CLC process constraints is not as straightforward. Pilot scale production of CLC particles by spray-drying has been achieved by different groups [47- 48], and scaling up is currently being addressed in the SUCCESS European Project. The cost of synthetic particles is significant and usually in the range of $10 € / \mathrm{kg}$. It is mainly determined by the cost of the selected starting materials (hence by the chosen formulation) and by the shaping method (spray-drying, granulating, spin-flash drying, etc.). Impregnating the active phase on a pre-shaped support adds an extra step to the preparation of the oxygen carriers, adding to its cost.

Fluidized bed testing of these synthetic oxygen carriers shows that they are adapted in terms of reactivity and oxygen transfer capacity. However stability of operation over time is still limited due to aging issues. This is a concern since aging will request particle addition to keep stable properties and clearly impact operating cost. De Diego et al. [49] observed attrition rate in the initial stage of the tests, but it did lower to 'acceptable' levels (e.g. $0.04 \mathrm{wt} \% / \mathrm{h}$ ) afterwards. C.R. Forero [50] shows that upon longer testing time, the attrition rate of these particles suddenly increases drastically (Fig.4). Wei et al. [51] also reported the pulverization of iron based synthetic particles $\left(\mathrm{Fe}_{2} \mathrm{O}_{3} / \mathrm{Al}_{2} \mathrm{O}_{3}, 70 / 30\right)$ after $60 \mathrm{~h}$ in a circulating fluidized bed.

Several studies have also been conducted with natural ores (and to a lesser extent with industrial waste materials). Indeed, natural ores are at least an order of magnitude cheaper than synthetic materials. As an example, the price of $\mathrm{Mn}$ ore and the price of ilmenite are in the range of 0.15$0.25 € / \mathrm{kg}$ [17]. To be used in the CLC process, ores must be processed so as to reach the required particle size distribution, which adds to the actual cost of the oxygen carrier to some extent. The crushed and sieved particles are not spherical, which will increase their initial attrition rate as well as the pressure drop in the risers. Among natural ores, ilmenite $\left(\mathrm{FeTiO}_{3}\right)$ and manganese ores have been particularly studied [52]. Their lower reactivity and oxygen transfer capacity compared to synthetic particles can be compensated by longer residence time in the fuel reactor. However, some studies suggest that manganese ores have poor mechanical stability and poor fluidizing properties making them unsuitable as oxygen carriers [53]. Stability is also an issue with ilmenite: the analysis of the used oxygen carrier shows that the porosity of the particles increases with time on stream, and that the chemical and mechanical transformations experienced by ilmenite particles in a $100 \mathrm{~kW}_{\text {th }}$ Chemical Looping combustor led to their breakdown into particles unfit for use in a circulating fluidized bed [54]. Expected lifetime of ilmenite has recently been estimated in the range of $300 \mathrm{~h}$, based on long term testing in a $100 \mathrm{~kW}_{\text {th }}$ circulating fluidized bed at Chalmers [55].

Aging of oxygen carrier is therefore presently a strong concern for both synthetic materials and natural ores. According to L.S. Fan et al. [25], the early studies on oxygen carriers for CLC applications failed to recognize the prevalent role of cationic and anionic migration inside the particles, which possibly entail the phase segregation reported above in ilmenite, as well as the formation of cavities/macropores, agglomeration and/or sintering. Our own experience [56] is consistent with this statement. Indeed, we observed large porosity increase with some manganese 
ores in IFPEN's $10 \mathrm{~kW}_{\text {th }}$ circulating fluidized bed, leading to the pulverization of some particles after $144 \mathrm{~h}$ of continuous combustion (387 cycles). With nickel based synthetic particles $\left(\mathrm{NiO} / \mathrm{NiAl}_{2} \mathrm{O}_{4}\right)$, a porosity increase and nickel migration was observed after 250 cycles in a batch fluidized bed, but the particles remained fluidized and reactive, while copper based particles $\left(\mathrm{CuO} / \mathrm{Al}_{2} \mathrm{O}_{3}\right)$ did not withstand the same number of redox cycles. The alumina matrix was shattered, leading to the formation of large amounts of fines, and copper migration/sintering was observed. The reasons for such differences in attrition behavior between natural ores and various synthetic particles are not yet fully understood, but promising results have been obtained in long term cycling experiments (up to 500 cycles) in batch fluidized bed with synthetic particles carefully designed to minimize metal ions migration. With regards to aging behavior in CLC processes, one therefore has to ensure that the particle's physical and chemical properties are not drastically evolving with the number of redox cycles, and long test periods should be favored.

The choice between natural ores and synthetic particles will very much depend on cost and on expected lifetime of the particles in the circulating fluidized bed. End of life and recycling of the fine particles generated in the CLC process have to be considered in the early stages as well. Indeed, aging of oxygen carriers in the industrial units will result in large amounts of waste materials heavily loaded with metals. Extensive research is still required to improve the properties of oxygen carriers. In general, oxygen transfer capacity and reaction kinetics are favorable with synthetic particles compared to natural ores, but there still is a need to improve their performance in terms of mechanical stability and active phase migration so as to be able to increase the number of cycles achievable in order to minimize $\mathrm{CO}_{2}$ capture cost.

\subsection{Pilot plants}

Chemical Looping Combustion is a complex process involving rapid contacting in opaque multiphase flow, with solid transportation at high temperature. It is therefore essential to develop appropriate experimental tools in order to support $R \& D$ and scale-up toward industrial applications.

Small scale reactors have been widely used over the last fifteen years to test and select appropriate oxygen carriers. Indeed, in thermal gravimetric analysis (TGA), very small amounts (milligrams) of materials are necessary. Therefore, TGA has been widely used for oxygen carrier screening studies. However, TGA use remains limited due to internal mass transfer limitations [57]. Small scale fixed bed and fluidized reactors have also been used [58]. These reactors are mostly used for gaseous feeds such as methane or syngas.

Batch operation is conducted by alternating oxidation and reduction conditions. Extensive cycling studies are possible but are usually limited (10-20 cycles typical in most cases). The cycling at this stage therefore remains rather small compared to the high number of cycles that is expected industrially (in the range of $10000-20000$ cycles minimum). When dealing with liquid and solid feedstocks, specific tools have to be developed in order to address feed introduction properly and achieve reasonable mass balances. These reactors are usually fluidized beds operating in batch $[35,40,59]$.

At IFPEN, using such reactors as shown in Fig. 5 and 6 with solid fuels, we could investigate reaction mechanisms at small scale while achieving reasonable mass balances in the range of 95$105 \%$ and injecting limited amounts of feedstocks in the range of $1 \mathrm{~g}$ [35]. It was also possible to evaluate the evolution of performances as a function of the number of cycles by automating the experiment for cycling (operating with gas injection only, however). Up to 500 cycles could be achieved on the same particle samples (unpublished work). However, when long term operation is desired on complex feeds with accurate mass balances, large scale continuous pilot plant is then obviously preferred and needed. 


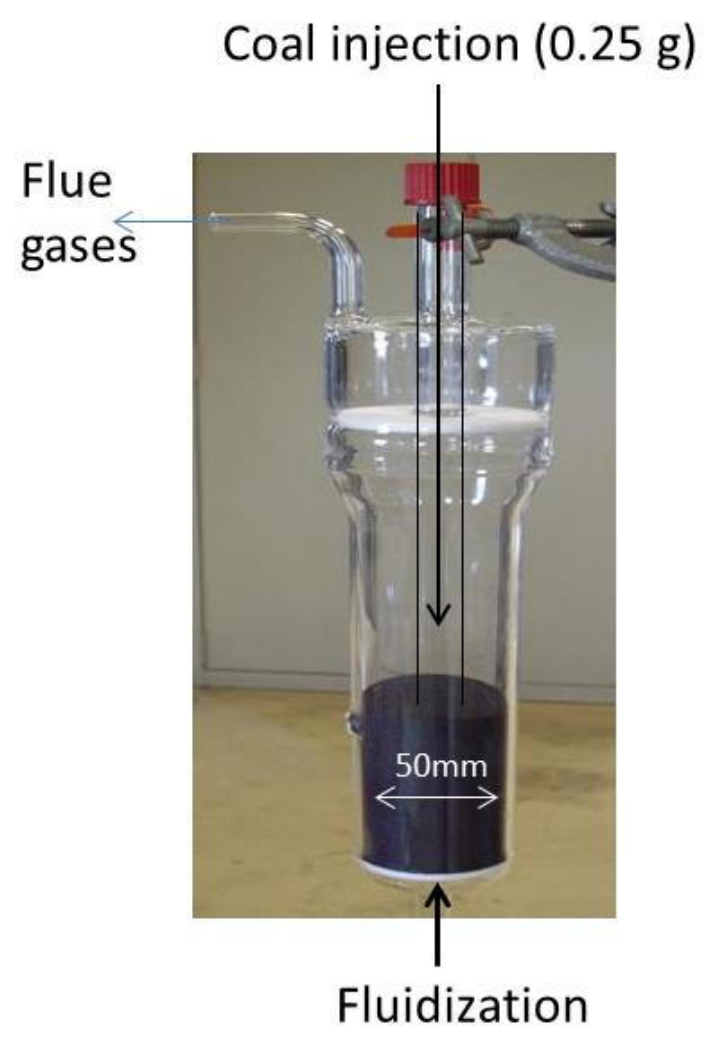

Figure 5: $50 \mathrm{~mm}$ i.d. batch fluidized bed reactor for solid fuel Chemical Looping Combustion [35]

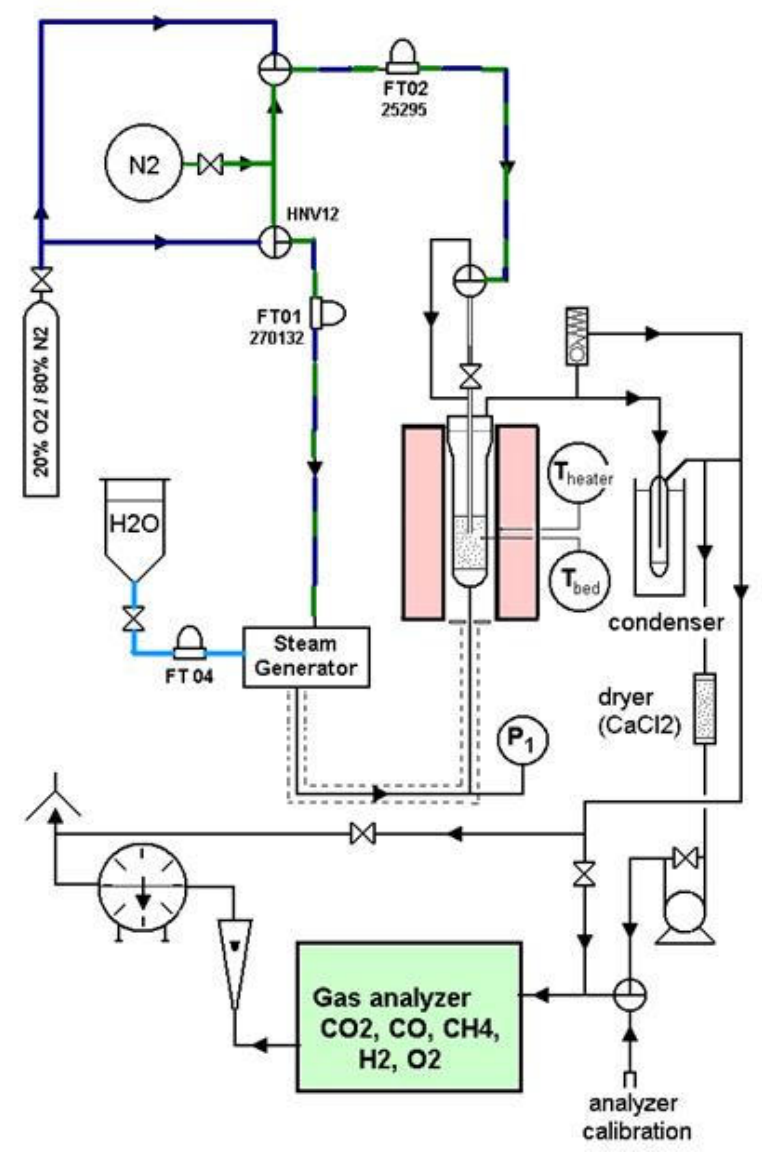

Figure 6: Experimental set up around the batch fluidized bed reactor [35]

For continuous pilot plant operation in CLC, separate reaction zones with continuous circulation of solids are needed. Apart from specific technologies related to CLC process constraints, since the pilot scale is usually small, due to the high temperature operation, thermal losses are important, and it is essential to compensate for heat losses at the wall and to thermally assist the operation during start-up. Several options are possible, among them: insert the whole pilot in a given furnace; specifically control temperature in each pilot section with dedicated heat tracers. Usually at small scale, due to heat compensation and control strategy, temperature in each reaction zone is fixed by the operator and results from the heat tracer compensation. This is a pseudo iso-thermal mode and it is different from expected industrial operation which is adiabatic. Heat balance calculation can support temperature selection in order to simulate pseudo adiabatic operation as a function of solid circulation. When the pilot size increases, heat compensation becomes more and more difficult due to increasing compensation required. At a certain scale, it becomes obvious to consider adiabatic operation while minimizing heat losses using insulation and refractory lining [60-61]. However, insulating large pilot plant piping with refractory is more difficult than insulating industrial plants due to the smaller size of piping. The temperature control strategy as a function of scale is therefore an important issue, that will clearly affect the results obtained and the cost of experiments. Similarly, depending on the pilot plant objectives, the reactor technology considered at the pilot scale can either be representative of industrial expected operation, or alternatively, the differences have to be accounted for when dealing with the results.

Over the last ten years, about twenty continuous pilot plants have been erected all over the world, with capacities ranging from $10 \mathrm{~kW}_{\text {th }}$ up to $150 \mathrm{~kW}_{\text {th }}$, as discussed by Adanez et al.[26]. Most of these units focused on gas and solid fuel testing, including a large pilot unit of $1 \mathrm{MW}_{\text {th }}$ built at Darmstadt [60-61] and a $3 \mathrm{MW}_{\text {th }}$ limestone CLC pilot plant unit at Alstom Power Plant laboratories 
[62]. Among these pilots, a number of pilot plant have been erected over the last five years in China [51, 63-66] in relation with the large coal combustion needs and concerns in this country. As an example, the $10 \mathrm{~kW}_{\text {th }}$ IFPEN pilot plant design [32] is represented in Fig.7. It was originally designed for methane and syngas combustion and, later, the fuel reactor was modified (see Fig.8) in order to study the combustion of solid fuels [36]. When the size of the pilot increases, operation complexity also increases and the amount of oxygen carrier required can be limiting due to the availability of materials. This is particularly true for synthetic materials.

As reported, in most of these pilots, it was possible to achieve continuous CLC combustion and to investigate the impact of operating conditions on fuel conversion during significant but limited time periods, resulting in limited redox cycling over time, (in the range of 100-200 cycles maximum typically). Indeed, it is not easy to maintain stable operation over long time periods with the same inventory at small scale, since oxygen carrier aging due to chemical or mechanical constraints attrition may create operation issues [54]. Depending upon pilot plant design and objectives, several important information can be consolidated. As an example, Lyngfelt and Linderholm [55] highlight the importance of volatiles flow control as a function of solid fuel distribution in the reactor. Clearly, based on all the work published, the CLC concept is well demonstrated at the pilot scale for gas and solid fuel combustion as well as for hydrogen production, but in most cases over a limited number of redox cycles in the range of 100-200 due to oxygen carrier aging limitations.

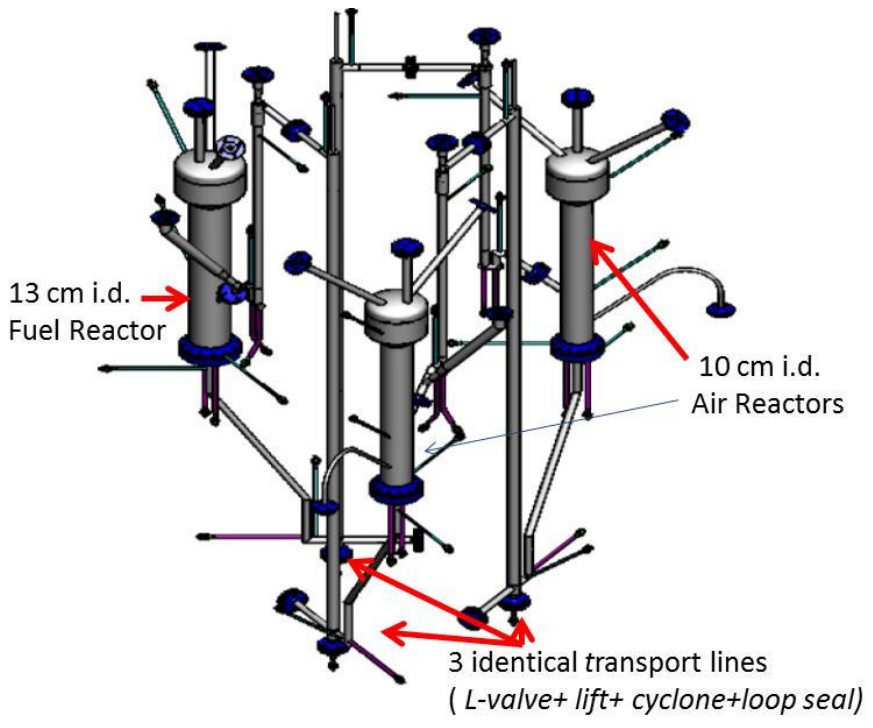

Figure 7: IFPEN $10 \mathrm{~kW}_{\text {th }}$ pilot plant lay-out for steady state gas CLC combustion study [32]

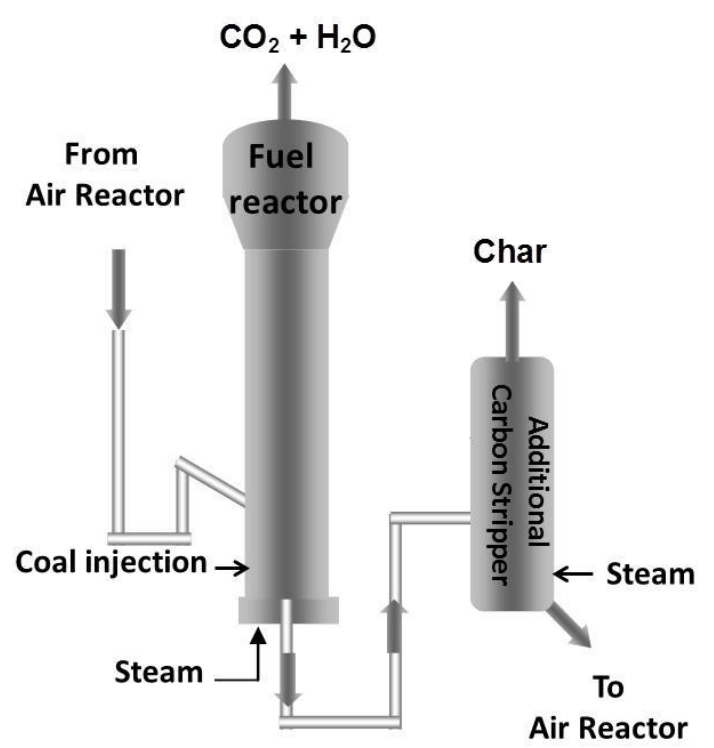

Figure 8: IFPEN $10 \mathrm{~kW}_{\text {th }}$ fuel reactor modified for solid fuel combustion study [36]

The next step is to demonstrate the technology over time at larger scale. However, for further developments, the challenges are numerous. Large scale testing is expensive and requires both confidence in the technology, oxygen carrier aging and market short term needs. Over the last years, $\mathrm{CO}_{2}$ prices falling and stabilizing in the range of $5 € / t$ have been very detrimental for short term perspectives in $\mathrm{CO}_{2}$ capture markets. At Total and IFPEN, we conducted a feasibility study and a basic engineering study to erect a $3 \mathrm{MW}_{\text {th }}$ demo unit (DECLIC project) in 2011-2012, as shown in Fig.9. With earlier CO2 markets, that unit would have been operating today [67]. At the same time, Cennovus [68] also had a $10 \mathrm{MW}_{\text {th }}$ CLC gas combustion unit project to produce SAGD steam in order to produce heavy oil bitumen in Canada that was not confirmed later. The most advanced Chemical Looping demo project is most likely the Ohio State University high pressure pilot syngas Chemical Looping unit at $250 \mathrm{~kW}_{\text {th }}$ to $3 \mathrm{MW}_{\text {th }}$ scale in Wilsonville, Alabama for $\mathrm{H}_{2}$ production [25]. According to L.Shen [69], the Chinese government is planning to support the fund to build an industrial pilot CLC device in the next 10 years, and the plan will be issued shortly. 


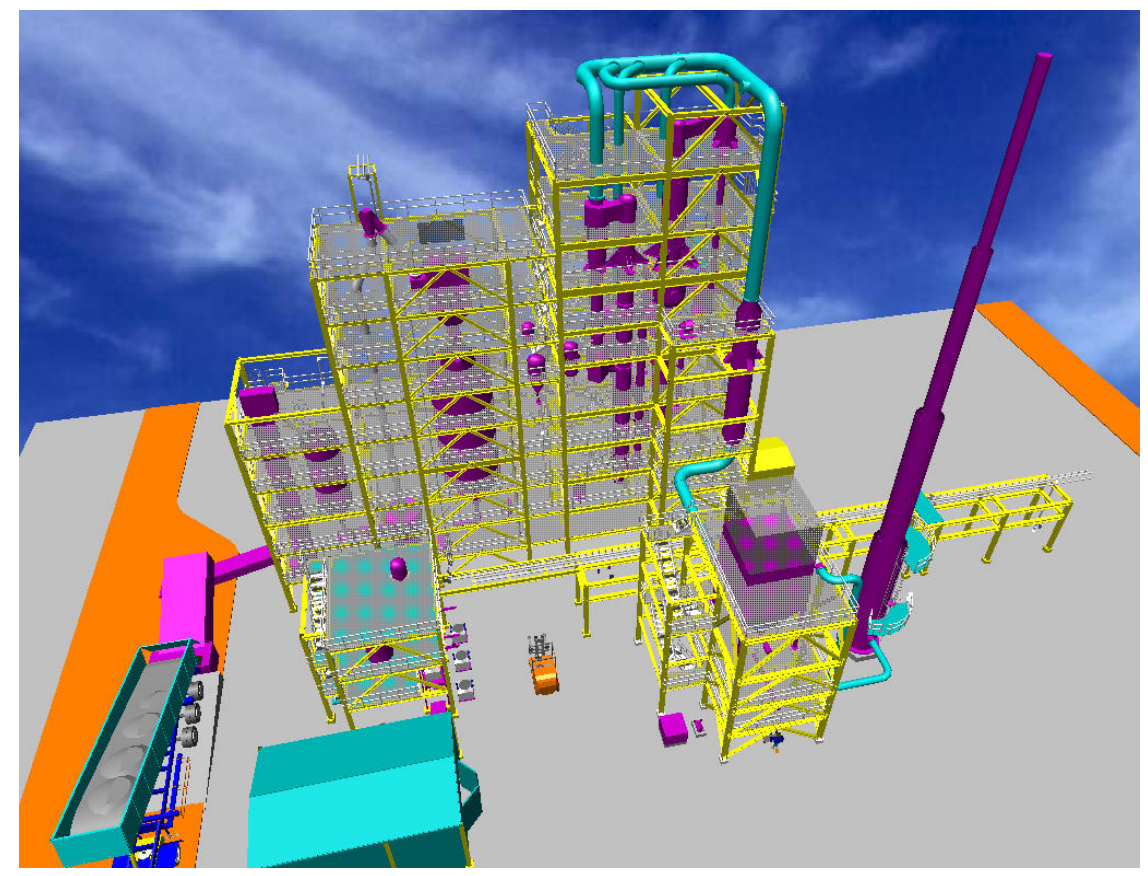

Figure 9: 3MW demo design for the Declic project [67]

\section{Fluidized bed technology for CLC}

Several technologies have been considered for CLC, including rotating reactors, alternating fixed beds, moving beds and interconnected fluidized beds systems [25-26]. For large scale applications such as coal combustion for power generation, fluidized bed technology is probably the most appropriate technology, offering the largest quantities of gas per unit cross section. Indeed, typical new CFB boilers nowadays have power generation capacities in the range of $250 \mathrm{MW}_{\mathrm{e}}[\mathbf{7 0}]$ and larger plants in the range of $500 \mathrm{MW}_{\mathrm{e}}$ have already been erected. In the future, CFB boiler capacity in the range of $800 \mathrm{MW}_{\mathrm{e}}$ are anticipated [70]. Therefore, it is mandatory to consider large power capacities as ultimate targets for CLC units dedicated to coal combustion with $\mathrm{CO}_{2}$ capture. Large scale operations are better optimized for energy efficiency (supercritical steam cycles as an example). Furthermore, CLC is the first step of the CCS process and large scale will also help to optimize and minimize costs related to transport and storage. Recently, EDF in France published a process investigation study for CLC coal combustion considering a $250 \mathrm{MW}_{\mathrm{e}}$ power plant electrical capacity [18]. In the past, scale-up of the technology was considered for $455 \mathrm{MW}_{\mathrm{e}}$ power plant capacity in Encap European project [71].

At a large scale, the circulation of large amounts of oxygen carriers has to be considered in between the air reactor and the fuel reactor. As an example, a rough calculation shows that a 200 $\mathrm{MW}_{\mathrm{e}}$ Coal CLC unit would require a solid circulation flowrate in the range of $2 \mathrm{t} / \mathrm{s}$, while considering an oxygen transfer $R_{0} \Delta x$ corresponding to $2 \%$ of the solid circulation flowrate. As a comparison, industrial FCC units operate with catalyst circulations typically in the range of $0.3 \mathrm{t} / \mathrm{s}$ to $1.5 \mathrm{t} / \mathrm{s}$ of catalyst. Also, in the early stage of R\&D it is important to have an estimate of the main equipment size in order to have an idea of the construction cost and assess the process feasibility. As a rough estimate, the same CLC unit discussed before would probably need an air reactor riser in the range of $11 \mathrm{~m}$ i.d. if considering gas superficial velocities in the range of $6 \mathrm{~m} / \mathrm{s}$. This is large compared to today's FCC risers, but rather small compared to large CFB boilers with cross sections in the range of $9 \times 21 \mathrm{~m}$. All this supports the fact that large CLC coal power plants are achievable, but process optimization and scale-up issues have to be carefully considered. 
Scale-up issues relate to reactor size and geometry, to solid circulation flowrates, but they also relate to the oxygen carrier chemical and mechanical stability over time, as pointed out above. Oxygen carrier stability issues have been encountered in pilot plants and to summarize where R\&D stands nowadays, oxygen carrier stability is presently limited in the range of $100-200 \mathrm{~h}$ of operation, which corresponds to 250-500 cycles. However, a large scale plant is expected to operate continuously with time on stream in the range of 8000 hours/year. Depending on the oxygen carrier stability, continuous addition will be needed to maintain a constant activity and inventory in the unit, and the amount of oxygen carrier added over a year can be compared to the oxygen carrier inventory in the unit. Without any addition, a stable oxygen carrier would probably cycle in the range of 30000 to 60000 times per year. If oxygen carrier addition corresponds to 1 inventory, the number of cycles will be divided by 2 .

We conducted a detailed estimate of $\mathrm{CO}_{2}$ avoidance cost for a large $630 \mathrm{MW}_{\mathrm{e}}$ coal power plant composed of $3 \times 525 \mathrm{MW}_{\text {th }}$ CLC plants in parallel. To assess the sensitivity of material cost and stability issue, the $\mathrm{CO}_{2}$ avoidance cost was estimated for a cheap natural ore (price delivered on site $=0.5 € / \mathrm{kg}$ ) and a cheap synthetic material (price delivered on site $=5 € / \mathrm{kg}$ ). The number of CLC unit inventories added per year for stability issues was varied from 1 to 6 , as shown on Table 3 below. Clearly, the impact on the $\mathrm{CO}_{2}$ avoidance cost is very significant for synthetic materials since the avoidance cost is multiplied by 2.5 when inventory is changed 1 or 6 times (corresponding to cycling capability reduction from 15000-30000 to 2000 to 5000 cycles typically. The impact is less important for natural ores. However, 2000-5000 cycles is about 10 times the maximum length of operation achieved up to now. Therefore, the oxygen carrier stability issue is also quite critical to consider and there is still a lot of work that needs to be conducted to improve material stability.

\begin{tabular}{|l|l|l|l|}
\hline Number of inventory renewal & 1 per year & 3 per year & 6 per year \\
\hline $\begin{array}{l}\mathrm{CO}_{2} \text { avoidance cost }\left(€ / \mathrm{t} \mathrm{CO}_{2}\right) \\
\text { with Natural Ore }(0.5 € / \mathrm{kg})\end{array}$ & 30.5 & 33.3 & 37.3 \\
\hline $\begin{array}{l}\mathrm{CO}_{2} \text { avoidance cost }(€ / \mathrm{t} \mathrm{CO}) \\
\text { with Synthetic Material }(5 € / \mathrm{kg})\end{array}$ & 42.6 & 69.4 & 109.6 \\
\hline
\end{tabular}

Table 3: $\mathrm{CO}_{2}$ avoidance cost as a function of number of solids inventory used per year

Reactor technology covering fluidization flow regime aspects, inlets and outlets configurations, appropriate geometry to control residence time and mixing, has to be optimized for performances as a function of process constraints. Apart from energy efficiency, $\mathrm{CO}_{2}$ capture efficiency (typically expected in the range of $90 \%$ ) needs to be considered, together with other important aspects such as the amount of unburnt coal and hydrocarbons in the flue gas to maximize combustion efficiency. Research has been conducted with several different pilot plants to investigate CLC combustion and the following conclusions were evident:

- coal combustion results from gasification of char (time limiting step) and combustion of syngas,

- unburnt coal / char has to be separated from oxygen carrier at the fuel outlet to maximize $\mathrm{CO}_{2}$ capture, and

- enough contact has to be provided between oxygen carrier, syngas and devolatilization materials for combustion efficiency.

At pilot scale, most of the pilot plants erected up to now use a bubbling fluidized bed fuel reactor with long residence time to promote coal gasification and syngas combustion. As discussed by Lyngfelt and Linderholm [55], coal feeding is essential to avoid bypassing of devolatilized materials. In their early pioneering work [33], solid fuel was introduced in the dilute phase of the 
fuel reactor, resulting in coal devolatilization and combustion bypassing for most of the volatile materials. In a more recent $100 \mathrm{~kW}_{\text {th }}$ unit [55], fuel is introduced with oxygen carrier in the upstream loop seal and enters the fuel reactor at the wall but they still observe some bypassing of devolatilized materials. They advise that adequate fuel distribution is important in large industrial fuel reactors in order to minimize this phenomena at large scale. Other options are also possible: coal can be injected with an independent transport line in order to maintain a low coal temperature and minimize devolatilization prior to fuel reactor contacting [36].

With solid fuels, fuel residence time must be large enough in the fuel reactor in order to allow char gasification. Recently, TU Vienna [72-73] proposed to increase fuel residence time in their CFB fuel reactor by installing ring internals all along the wall of the CFB. Such a configuration has being used in riser sections of FCC units [74] Furthermore, ring internals limit overall solid mixing and this gives the possibility to achieve a countercurrent behavior of gas and solid. Counter-current approach is also proposed by TU Hamburg in their fuel reactor concept, but implemented in a two stage dense fluidized bed [75]. Residence time in the reactor also relates to the particle size of the solid fuel particles. Pulverized fuels are expected to react faster but will also be quickly entrained by transport gas from the fuel reactor conversion section, while large particles may react slowly but shall stay longer in the fuel reactor [61]. The fuel particle size is also important to consider for separation at the outlet of the fuel reactor since the exiting unburnt char particles will be recycled to the fuel reactor a topic discussion below.

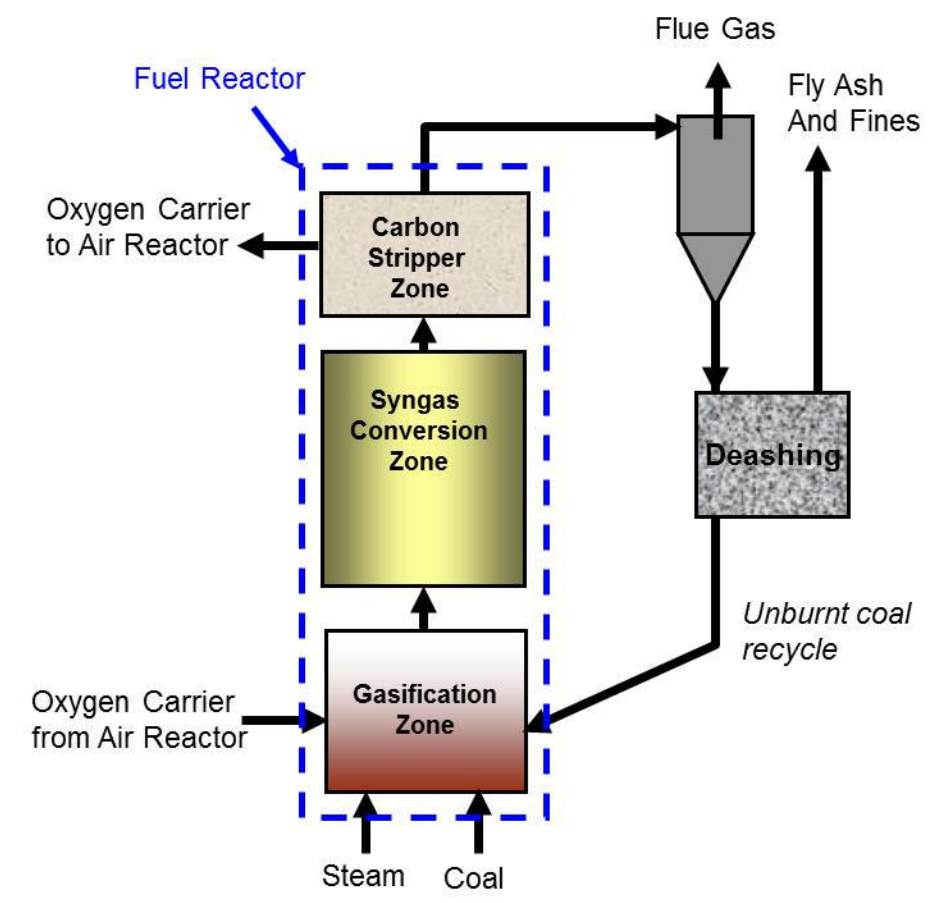

Figure 10: the fuel reactor concept developed by IFPEN and Total [67]

There are several possible options to be considered for the combustor technology developments, as discussed above. Based on the reactions constraints and design criteria, some options may scale-up better than others. In our IFPEN-Total research group, we developed a new fuel reactor concept while analyzing reaction constraints combined with scale-up perspectives [67]. The reactor technology was adjusted to meet the CLC process constraints in order to maximize $\mathrm{CO}_{2}$ capture and minimize energy penalty. In details, the CLC reaction zone is composed of two sections (fuel reactor/ air reactor). L-valves and Loop-seals are used to control solid circulation and gas leakage in between the reactors. A new fuel reactor design is proposed, as shown in Fig.10. The design provides enough time for gasification reaction in a first coal - oxygen carrier contacting zone consisting of a high velocity turbulent fluidized bed zone, All the effluents exiting from this 
zone then enter a riser transport section that provides enough contact time for syngas and volatiles combustion. The effluents then flow through an integrated carbon stripper to separate unburnt coal and ash from oxygen carrier. Unburnt coal and fly ash are recycled back toward the fuel reactor. A $60 \%+$ carbon conversion per pass is anticipated which would result in more than $90 \% \mathrm{CO}_{2}$ capture rate. The air reactor is designed as a circulating fluidized bed in order to achieve at least $90 \% \mathrm{O}_{2}$ capture from the air and minimize energy penalty. The oxygen carrier flow is controlled by L-valves which can adjust the circulation in between each reaction zone.

\subsection{Control of circulation : L-valves}

Control of solids circulation is critical in order to control reactor performance in CLC. Indeed, in adiabatic industrial conditions, solid circulation will provide heat transportation between the air and the fuel reactor. As a consequence, solid flowrate will not only affect the reduction rate of the oxygen carrier, but also the temperature difference between air and fuel reactor. Due to high temperature conditions in CLC, the use of conventional mechanical valves is not economically feasible. Thus, non mechanical L-Valves were considered [76]. However, the use of L-valves then imposes to use particles belonging to group B of Geldart's Classification in order to obtain fine circulation tuning, as theses valves are not capable of controlling Geldart Group A powder flow.

The solids flow in non-mechanical valves results from drag forces exerted by aeration gas on the particles in bends. As represented in Fig.11, an L-valve is a simple non mechanical valve composed of an elbow combined with an aeration located at the bottom of a standpipe. The actual flow that causes the solids to flow around the L-valve is not just due solely to the amount of external aeration added to the valve. Indeed, some gas is travelling up or down the moving packed bed standpipe with the solids. Thus, the amount of gas that flows around the L-valve bend is the sum of the standpipe gas internal flow and the aeration gas external flow. If the gas is flowing up the standpipe, then the amount of gas flowing around bend is the difference between the aeration gas external flow and the gas flowing up the standpipe [76-81].

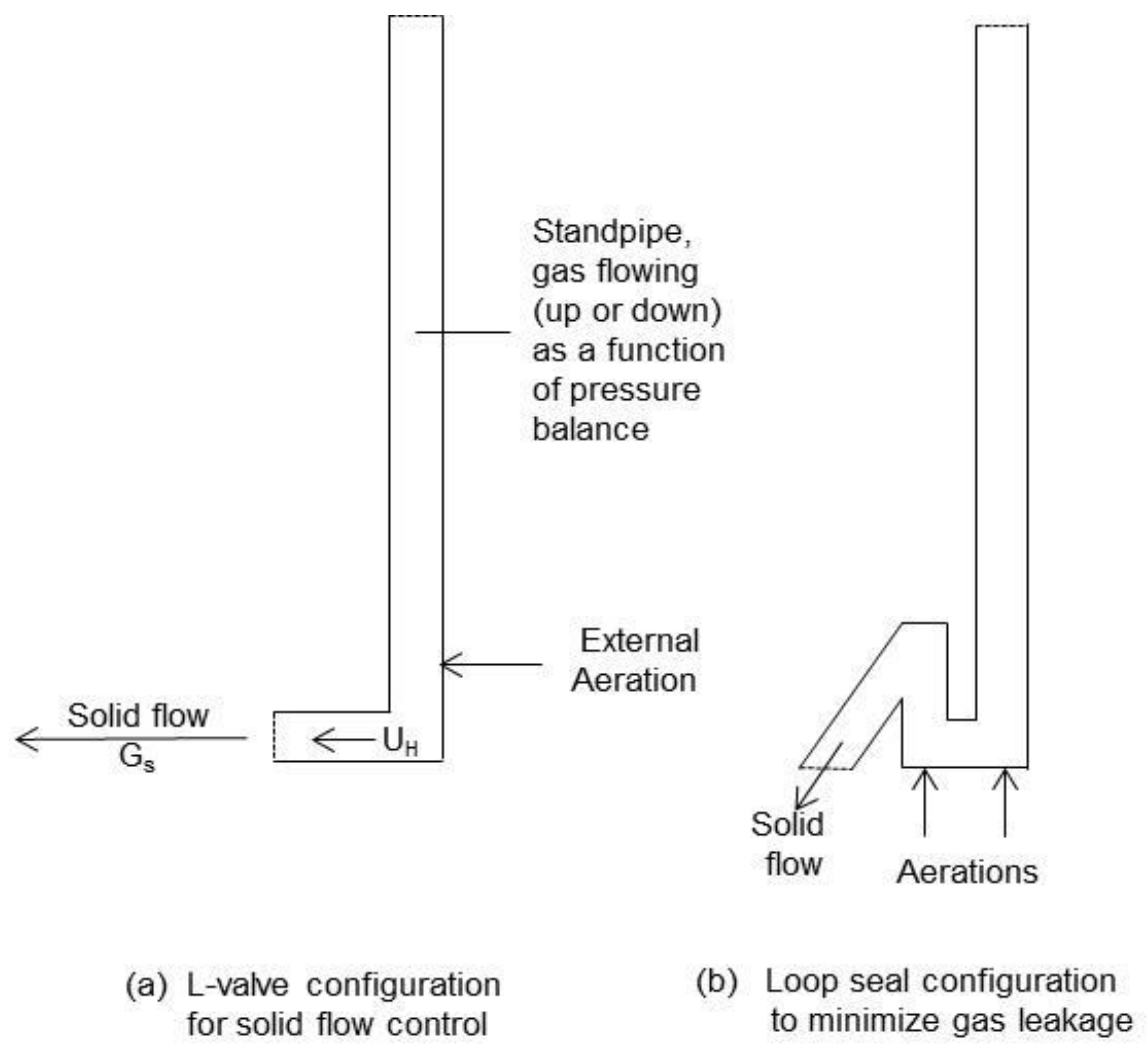

Figure 11 : L-Valve and loop seal configurations 
When aeration is added to a non-mechanical valve, solids do not necessarily start to flow immediately and the amount of initial aeration gas added to unlock solid circulation depends on several parameters. Above this threshold, additional aeration gas added to the valve will cause an increase in solid flowrate. Non mechanical valves work best with Geldart Group B and D materials with particle size typically larger than 100 microns [80]. In general, L-valves cannot be used with Geldart's group A to control the flowrate of solids, since in most cases, the flow would remain fluidized in the standpipe.

Knowlton and Hirsan [78] have already shown in 1978 that the operation of a non-mechanical valve is dependent upon pressure balance and geometry of the system. Recent experimental work conducted with different L-valve sizes (from $20 \mathrm{~mm}$ to $240 \mathrm{~mm}$ ) and different solids (ilmenite, sand and manganese ore) at ambient conditions [76-77, 82] show the link between the resulting solid flux $G_{s}$ in the $L$-valve as a function of the actual gas velocity in the horizontal section of the L-valve $\left(U_{H}\right)$ and minimum fluidization gas velocity $\left(U_{m f}\right)$ ratio (see Fig.12 below). Depending on gas flow, very large solid mass flux can be obtained.

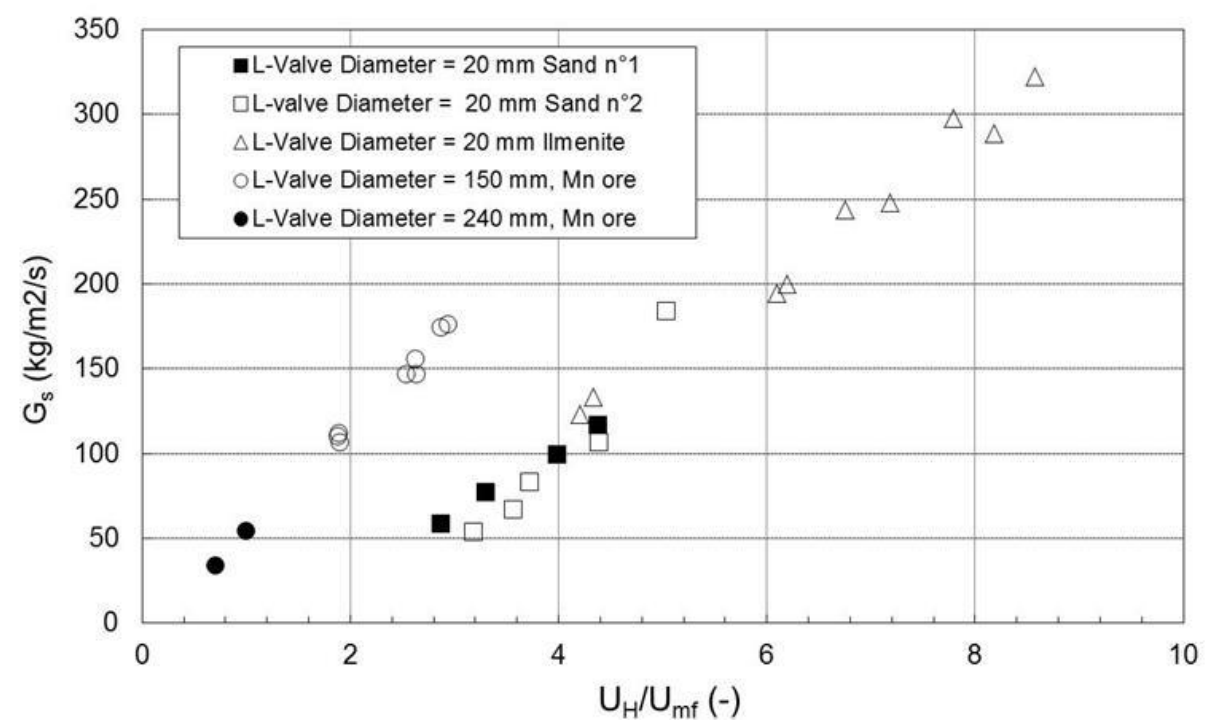

Figure 12 : Solid flux as a function of adimensionnal gas flow in the L-valve

The same trend can be found at elevated temperatures in the range of $25-7500^{\circ}$ [80-81]. Based on all this, a general expression can be derived to model resulting solid mass flux:

$G_{s}=k\left(\frac{U_{H}}{U_{m f}}\right)+G_{0}$

The gas velocity $U_{H}$ in the horizontal section results from external aeration added to the L-valve and from gas flowing up or down in the standpipe, that needs to be evaluated as a function of pressure balance. The value of $\mathrm{G}_{0}$ and $\mathrm{k}$ relate mostly to the $\mathrm{L}-\mathrm{V}$ alve geometry and particle properties [81].

In some cases, it is not necessary to control solids circulation but only to minimize gas leakages in between two interconnected fluidized bed systems. As an example, in CLC it is important to minimize dilution of the produced $\mathrm{CO}_{2}$ stream exiting fuel reactor by nitrogen coming from air reactor, or to minimize $\mathrm{CO}_{2}$ leaks from fuel reactor to maximize $\mathrm{CO}_{2}$ capture. For that purpose, loop-seals, as represented in Fig.11, can be used considered in CLC units, as discussed by Yazdanpanah et al.[83]. L-valve and loop-seal operations have some similarities, as discussed in [81-83]. 


\subsection{CLC circulating solid particles composition issues}

Another aspect of solid circulation in CLC that is not often discussed relates to the solids composition in the process, that is quite complex and changes significantly in the loop depending on the location. Indeed, a coal combustion process can generate agglomerated and/or fly ash depending upon coal composition and operating conditions (mostly temperature). On one hand, if agglomerated ash is generated, it will accumulate at the fuel reactor bottom and withdrawal has to be considered. On the other hand, fly ash, which is made of very fine particles, will exit the reactor in flue gas. If a high efficiency cyclone is implemented on flue gas to recover fine char particles, then a lot of fly ash will also be recovered and will therefore accumulate in the unit and progressively modify significantly the PSD of circulating particles in the fuel reactor. It may therefore be important to implement a deashing zone (as shown on Fig.10).

It is also important to implement a separation zone to separate char particles from oxygen carrier in the loop at the fuel reactor outlet. Char particles entrained with flue gas would generate losses in energy efficiency and char entrained with the oxygen carrier would generate a decrease of the $\mathrm{CO}_{2}$ capture efficiency. In practice, in order to limit entrainment of char to the air reactor and to maximize $\mathrm{CO}_{2}$ capture efficiency, a carbon stripper section dedicated to char separation and recycling back to reactor fuel can be implemented. Several designs have been proposed, mostly based on fluidized bed elutriation, either integrated in the dense phase of the fuel reactor [33], or implemented in between the fuel reactor and the air reactor [55-71]. As an example, Alstom [71, 84] has developed a separator based on entrainment in a compartmented fluidized bed located in between the fuel reactor. In our IFPEN-Total research group, we have developed an alternative concept based on dilute phase separation at the fuel reactor with the flue gases to minimize energy penalty [85]. This concept was tested in a $0.6 \mathrm{~m} \mathrm{I.D,} 1 \mathrm{MW}_{\text {th }}$ equivalent large cold flow model and in our $10 \mathrm{~kW}_{\text {th }}$ pilot plant [36].

\subsection{Oxygen carrier attrition}

As discussed before, oxygen carrier aging and losses significantly impact the economics of the process. During their life-time, particles go through high mechanical, chemical and thermal stresses related to circulation in the process loop. Therefore, apart from reactivity, oxygen transfer capacity and reactive cycling aging of oxygen carrier materials, it is also important to study the oxygen carrier resistance to attrition. Apart from economical consideration, particles with low mechanical resistance will produce fines that can cause many operation problems related to inventory losses and solids circulation problems. In the perspective of industrial operation, attrition needs therefore to be minimized. Unfortunately, there is presently very little information available concerning long term operation with group B oxygen carriers and there is no industrial data available to be used as a reference for the CLC process. It is therefore difficult, in the early stage of process developments, to predict attrition at industrial scale based on existing tools and methodologies for the different oxygen carriers available at small production scale. Attrition relates to solids properties and fluidization conditions (i.e.particle velocities). As discussed before, solids properties deteriorate after a few hundreds of cycles. It is important therefore to consider equilibrium solid properties to evaluate attrition due to mechanical stress in fluidization conditions, but which equilibrium condition to consider?

To evaluate the attrition due to mechanical stress, a first approach is to relate attrition to the principal sources of particle breakage such as cyclones, gas injections and gas bubbles in fluidized beds. The modeling of attrition sources can then be conducted with a population balance model in order to predict attrition at an industrial case. J. Werther and E. Hartge [86] used this method to predict the attrition generated in a reactor/ regenerator system. Based on this approach, more recently, Kramp et al. [87] made an attempt to simulate attrition in a CLC process. This method is presently the most suitable approach to evaluate attrition at industrial scale, however it requires a tedious experimental work and a large quantity of material of interest in order to characterize the 
different sources of attrition. For particle screening or when little amount of particles is available , as it is usually the case at the early development stage, it cannot be applied.

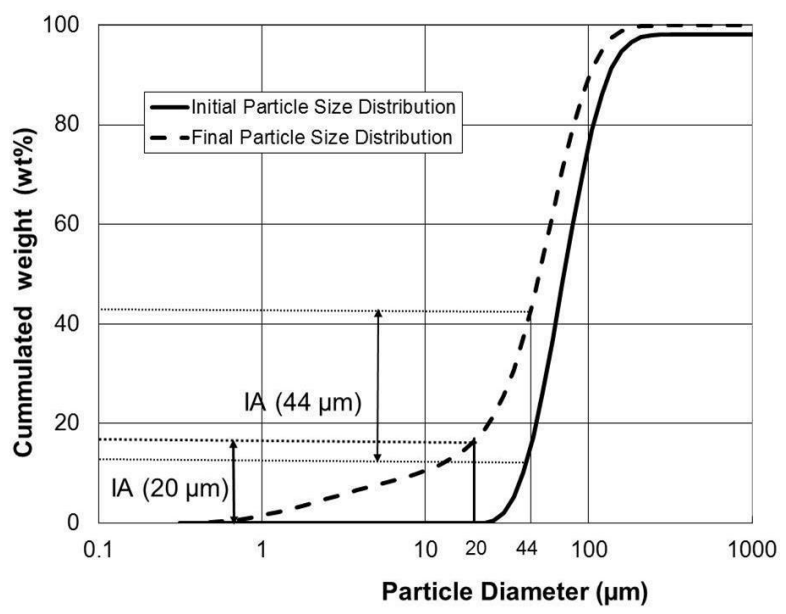

Figure 13. standard attrition indexes $I \mathrm{~A}_{20}$ and $\mathrm{IA}_{44}$ [89]. Illustration with FCC catalyst attrition results

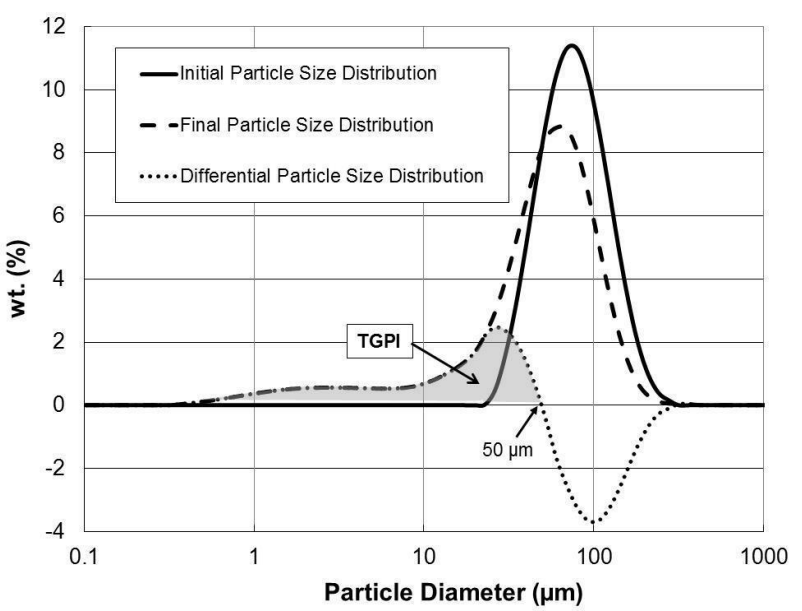

Figure 14: New TGPI attrition index proposed [88]. Illustration with FCC catalyst attrition results

In order to evaluate the resistance to mechanical attrition of the different oxygen carriers available, we proposed a relative method in order to compare oxygen carrier resistance to spent catalyst resistance in Fluid Catalytic Cracking process (FCC) [88]. Indeed, the CLC process configuration is similar to the FCC process with a controlled solid flow circulating in a loop of reactors. Therefore, in both processes, particles go through a similar mechanical stress. FCC particles can therefore be used as a reference in order to evaluate and rank the mechanical resistance to attrition of the different oxygen carriers available. However, since FCC particles belong to the fluidization Group $A$, while oxygen carrier particles usually belong to the fluidization Group B, direct comparison is neither easy nor obvious to conduct using standard attrition tests. For this reason, we developed a specific method using a lab scale jet cup rig [89] in order to compare the mechanical resistance to attrition of different kinds of particles. First, to account for PSD differences, we defined a new attrition index that does not depend anymore upon a given particle size, as usually proposed (see Fig.13). This index is based on the total percentage of particles generated by attrition and it is called TPGI (Total Particles Generated Index), as shown in Fig.14.

With the revised attrition method, we found that attrition is proportional to the contact frequency between the air jet and the particles in the jet cup attrition test [88]. Therefore it is necessary to estimate the particles circulation within the air jet for each solid tested in order to make sure that particles go through the same mechanical stress. Based on this, it is possible, using Computational Fluid Dynamics (CFD), to evaluate the inventory required as a function of particle properties to generate similar stress. Our results showed that in order to have the same circulation of particles in the air jet (therefore the same mechanical stress during attrition test) tests should be carried out with the same initial volume of particles [88]. Further experimental validation is required to consolidate this conclusion. Based on this, the particles mechanical resistance can be characterized by the TPGI increase rate with respect to the jet cup test duration and comparison can be made using different solids in conditions developing similar stress.

It is important to notice that this attrition testing procedure allows to compare solids relatively, meaning that it is possible to know that one solid will behave better with respect to the other in terms of attrition. However it is difficult to get quantitative attrition data at industrial scale from this test. To move a step forward, we need to relate the jet cup attrition tests results to the attrition occurring in the principal sources of attrition in the process, such as cyclones and gas injectors. The jet cup results could then be transposed to the attrition at industrial scale using a population balance model. 


\subsection{Fluidized regimes in CLC process}

For design aspects, scale-up and control of operating conditions, it is important to study and characterize the flow regimes and hydrodynamics in the air reactor and in the fuel reactor. In the fuel reactor with solid fuels, as discussed before, the fuel residence time may be limiting due to slow gasification reactions, as noted above. Thus, for industrial scale operations, the fuel reactor diameter needs to be minimized, and therefore, high fluidized bed velocities in the turbulent regime need to be considered [90-92]. However, there is still limited information on turbulent fluidization in the literature for Group B powders at elevated temperatures, and some work is still needed in order to predict turbulent transition, the bubbling/slugging behavior and the solids mixing with turbulent fluidization. This is particularly true for high density materials such as oxygen carriers considered for CLC applications [82].

Oxygen carrier oxidation with air is a fast reaction that can be conducted in a circulating fluidized bed with high velocities. To minimize the amount of air flowrate, oxygen consumption has to be maximized (at least 90\%) with air reactor oxidation step. Therefore, the design should allow enough air / oxygen carrier contacting in the riser. Another design constraint relates to the minimization of energy penalty. Indeed, energy consumption in the CLC process is mainly related to air compression upstream the air reactor. Due to the large amount of air required, we could estimate that an increase of the air reactor pressure drop in the range of 100 mbar would result in a loss of $0.5 \%$ for the overall CLC process energy yield, which is very significant (see Table 1). Based on literature, prediction of riser flow with dense group B particles densities exceeding 3000 $\mathrm{kg} / \mathrm{m}^{3}$ is presently a difficult task. Therefore, we performed large scale experiments in a $18 \mathrm{~m}$ high riser with a $0.3 \mathrm{~m}$ diameter, with different group B particles [93-94], at expected representative gas velocities in the range of $8-10 \mathrm{~m} / \mathrm{s}$ and solid mass fluxes in the range of $30-60 \mathrm{~kg} / \mathrm{s} / \mathrm{m} 2$. As shown in Fig. 15 below, for similar operating conditions, the sand and glass beads that were tested generated very different pressures drops.

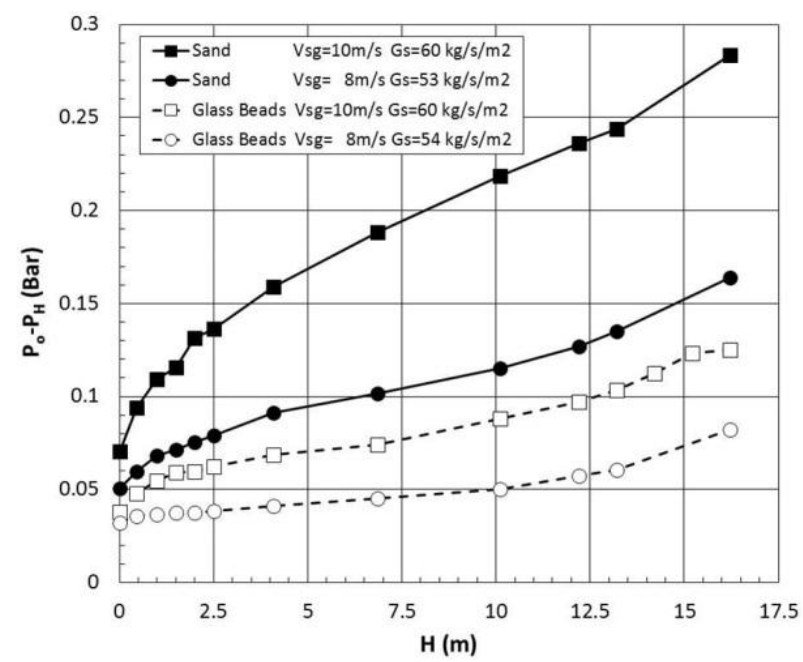

Figure 15: Axial pressure profiles along the riser for sand and glass beads (GB) at different operating conditions.[94]

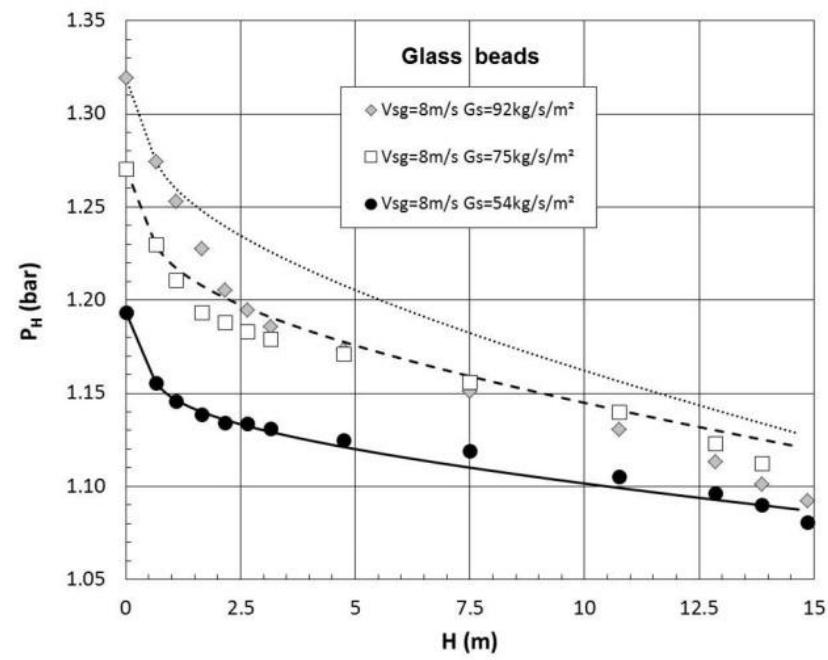

Figure 16: Experimental and 1D model prediction of axial pressure profiles along the riser with glass beads [95]

Pressure drops for glass beads, with a sphericity of 1 , are consistently smaller than those obtained with a sand of similar size, but with a sphericity of 0.83 . This suggests that particle sphericity has a substantial impact on hydrodynamics and may also impact energy penalty of the process. These differences may be explained in part by a larger annulus region with non-spherical particles. However, the impact of sphericity that we found is strong and unexpected. It cannot be predicted by the classic riser models nor CFD [95]. Therefore, we developed a 1D model at IFPEN using these experiments to derive a 1D drag force, and accounting for particle properties in order to predict riser hydrodynamics in CLC conditions (see Fig.16). With such a model, drag force 
adjustment is essential to describe properly particle acceleration at the riser bottom. In the present case, the drag adjustment was satisfactory at low mass fluxes in the CLC expected conditions but at higher mass fluxes in the range of $90 \mathrm{~kg} / \mathrm{s} / \mathrm{m}^{2}$, the resulting acceleration of particles was too strong.

\section{Conclusions}

To summarize, at present, $\mathrm{CO}_{2}$ market value and incentive policies remain limited, despite increasing global warming concerns. In this context, even if $\mathrm{CO}_{2}$ storage capacities are available, the economics and public acceptance limit CCS deployment. It is therefore difficult to justify the deployment of CCS industrial projects without additional side profits such as EOR for instance. $\mathrm{CO}_{2}$ use is an interesting route to consider as a complement to $\mathrm{CO}_{2}$ storage. However, even if the $\mathrm{CO} 2$ use would generalize at large scale, the impact will probably remain limited and most of the $\mathrm{CO}_{2}$ will have to be stored. The perspectives are improving slowly and $\mathrm{CO}_{2}$ price is expected to grow progressively in the next 15 years.

Some $\mathrm{CO}_{2}$ capture technologies are already used industrially. However, these technologies suffer from large penalties and require significant investments. In order to reduce $\mathrm{CO}_{2}$ avoidance cost and impact on energy supply cost, new $\mathrm{CO}_{2}$ capture techniques such as CLC will be required.

CLC is a promising alternative solution for $\mathrm{CO}_{2}$ capture that minimizes energy penalty. In the past years, a huge effort has been conducted worldwide to investigate CLC materials and process issues. Nowadays, the CLC concept is well demonstrated on the pilot scale. These results confirm the CLC potential for $\mathrm{CO}_{2}$ capture compared to other solutions. However, oxygen carrier stability needs to be improved in order to minimize the operating cost and resulting $\mathrm{CO}_{2}$ avoidance costs.

Due to the large amount of $\mathrm{CO} 2$ emissions resulting from coal combustion in large power plants in the world, CLC developments should really address this market on a long term perspective. As discussed, CLC combustion for solid fuels is probably more challenging and specific technology developments need scale-up and industrial validation.

Over the last few years, most of the development roadmaps for CCS have been delayed by roughly ten years, from 2015-2020 to 2025-2030 compared to the ambitious plans that were considered before 2010. Short term market for $\mathrm{CO}_{2}$ capture is limited, but the need for CCS technologies remains as part of the global warming mitigation solutions. This is challenging since short term industrial developments financing is more difficult. However, this delay may also be considered as an opportunity, specifically for new promising processes such as CLC in order to optimize oxygen carrier materials and technology. The next step is to demonstrate the technology over time at larger scale in order to achieve long term industrial operation with a reliable material.

\section{Acknowledgements:}

The authors would like to acknowledge the research teams from Total and IFPEN that have been actively involved and collaborating in the Chemical Looping Combustion project over the past eight years. 


\section{References}

[1] Key trends in $\mathrm{CO}_{2}$ emissions : IEA Statistics (2015) Edition, www.iea.org/publications

[2] Technology Roadmap Carbon capture and storage - 2013 edition. IEA (2013), www.iea.org/publications

[3] Global CCS Institute, The Global Status of CCS, 2015 Summary report (2015), www.globalccsinstitute.com

[4] Leung D. Y.C., Caramanna G., Mercedes Maroto-Valer M. , An overview of current status of carbon dioxide capture and storage technologies, Renewable and Sustainable Energy Reviews (2014) 39 426-443

[5] Bachu S., Bonijoly D., Bradshaw J., Burruss R., Holloway S., Christensen N.P., Mathiassen O.M.. $\mathrm{CO}_{2}$ storage capacity estimation: Methodology and gaps. International Journal of Greenhouse Gas Control (2007) 1430-443

[6] Rubin E.S., Davison J.E., Herzog H.J., The cost of $\mathrm{CO}_{2}$ capture and storage, International Journal of Greenhouse Gas Control (2015) 40 378-400

[7] GeoCapacity Final Report, (2009) www.geocapacity.eu

[8] Schumann D, Duetschke E., Pietzner K., Public perception of $\mathrm{CO}_{2}$ offshore storage in Germany: regional differences and determinants, Energy Procedia (2014) 63 7096-7112

[9] Ashworth P., Wade S., Reiner D., Liang X., Developments in public communications on CCS. International Journal of Greenhouse Gas Control (2015) 40, 449-458

[10] Kerlero de Robso G. Rakotojanoa L., De Bucy J., Valorisation chimique du $\mathrm{CO}_{2}$, Etat des lieux, Valorisation chimique du $\mathrm{CO}_{2}$ : état des lieux. Quantification des bénéfices énergétiques et environnementaux et évaluation économique de trois voies chimiques (2014) Ademe, France, http://www.ademe.fr

[11] Waldstein G, Catalytic methanation- the Audi e-gas project as an example of industrialized technology for power to gas (2015), proceeding of the Regatech Conference , 7-8 May 2015, Barcelona, Spain, 67-68

[12] Stanger R, Wall T, Spörl R, Paneru M, Grathwohl S, Weidmann M, et al. Oxy-fuel combustion for $\mathrm{CO}_{2}$ capture in power plants, Int J Greenh Gas Control (2015) 40, 55-125.

[13] Pham J, Lethier S, Marcano N, Recourt P. Operating experience and performance characteristics of a gasoxycombustion technology at Total's Carbon Capture and Storage demonstration plant. Technical paper BR 1890, Power-Gen Int. (2012) Orlando, Florida, U.S.A

[14] Cuellar-Franca RM, Azapagic A. Carbon capture, storage and utilisation technologies: a critical analysis and comparison of their life cycle environmental impacts. $\mathrm{J} \mathrm{CO}_{2}$ Util (2014) 9, 82-102

[15] Goto K, Yogo K, Higashii T. A review of efficiency penalty in a coal-fired power plant with post-combustion $\mathrm{CO}_{2}$ capture, Appl Energy (2013) 111, 710-720

[16] Raynal, P. A. Bouillon, A. Gomez, P. Broutin, From MEA to demixing solvents and future steps, a roadmap for lowering the cost of post-combustion carbon capture. Chem. Eng. J. (2011) 171, 742-752.

[17] JC Abanades, B.Arias,A.Lyngfelt, T.Matisson, D.E. Wiley, H.Li, MT Ho, E.Mangano and S.Brandani, Emerging $\mathrm{CO}_{2}$ Capture systems, International Journal of Greenhouse Gas Control , (2015) 40,126-166

[18] Authier O, Le Moullec Y. Coal Chemical-Looping Combustion for electricity generation: investigation for a $250 \mathrm{MW}_{e}$ power plant. Energy Procedia (2013) 37 588-597

[19] Ekström C, Schwendig F, Biede O, Franco F, Haupt G, de Koeijer G, et al. Techno-economic evaluations and benchmarking of pre-combustion $\mathrm{CO}_{2}$ capture and oxy-fuel processes developed in the European ENCAP project. Energy Procedia (2009) 1, 4233-4440

[20] Wennersten R., Sun Q., Li H., The future potential for Carbon Capture and Storage in climate change mitigation an overview from perspectives of technology, economy and risk. Journal of Cleaner Production (2015) 103 724-736

[21] BP Statistical Review of World Energy (2015), www.bp.com

[22] Luckow P., Stanton E.A., Fields S., Biewald B., Jackson S., Fisher J., Wilson R., Carbon Dioxide price forecast (2015) Synapse Energy Economics, http://www.synapse-energy.com

[23] Ishida, M.; Jin, H., A new advanced power-generation system using chemical-looping combustion, Energy (1994), $19,415-422$

[24] Ishida, M.; Zheng, D.; Akehata, T., Evaluation of a chemical-looping-combustion power-generation system by graphic exergy analysis Energy (1987) 12, 147-154.

[25] Fan L.S., Zeng L., Luo S., Chemical Looping Technology Platform, AIChE Journal (2015) 61, 1, 2-22

[26] Adanez J., Abad A, Garcia-Labiano F., Gayan P., De Deigo L.F, Progress in Chemical Looping Combustion and reforming technologies, Progress in Energy and Combustion Science (2012) 38, 2, 215-282

[27] Zhao C.W., Chen X.P., Anthony E.J., Jiang X., Duan L.B., Wu Y. Dong W., Zhao C.S., Capturing CO2 in flue gas from fossil fuel fired power plants using dry regenerable alkali metal-based sorbent, Progress in Energy and Combustion Science (2013) 39, 6 515-534 
[28] Lyngfelt A, Kronberger B, Adánez J, Morin J-X, Hurst P., The Grace project. Development of oxygen carrier particles for chemical-looping combustion, design and operation of a $10 \mathrm{~kW}$ Chemical-Looping combustor. In: Proc $7^{\text {th }}$ Int Conf Greenhouse Gas Control Technology -GHGT 7 (2004, Vancouver, Canada;

[29] Adánez J, de Diego LF, García-Labiano F, Gayán P, Abad A., Selection of oxygen carriers for Chemical Looping Combustion. Energy \& Fuel (2004)18, 371-317.

[30] Ryu H.J, Jin G-T, Yi C-K. Demonstration of inherent $\mathrm{CO}_{2}$ separation and no NOx emission in a $50 \mathrm{~kW}$ Chemical Looping combustor: Continuous reduction and oxidation experiment. In: Proc 7th Int Conf Greenhouse Gas Control Technology -GHGT7 (2004), Vancouver, Canada.

[31] Pröll T, Kolbitsch P, Bolhàr-Nordenkampf J, Hofbauer H. Demonstration of Chemical Looping Combustion at relevant operating conditions, In "Carbon dioxide capture for storage in deep geological formations results from the $\mathrm{CO}_{2}$ capture project" (2009) 3, 7 75-84 CPL Press (UK), Eide LI, editor

[32] Yazdanpanah MM, Hoteit A, Forret A, Delebarre A, Gauthier T. Experimental investigations on a novel Chemical Looping Combustion configuration. Oil Gas Sci. Technol. (2011) 66, 265-75.

[33] Berguerand N, Lyngfelt A. Design and operation of a $10 \mathrm{kWth}$ Chemical Looping combustor for solid fuels - Testing with South African coal, Fuel (2008) 87, 2713-2726.

[34] Berguerand N, Lyngfelt A. The use of petroleum coke as fuel in a $10 \mathrm{~kW}$ Chemical Looping combustor. Int J Greenhouse Gas Control (2008) 2, 169-179.

[35] Stainton H. , A. Ginet, K. Surla, A. Hoteit, Experimental investigation of CLC coal combustion with nickel based particles in a fluidized bed, Fuel (2012) 101, 205-214

[36] Sozinho T, Pelletant W., Stainton H., Guillou F., Gauthier T., Main results of the $10 \mathrm{~kW}$ th pilot plant operation, '2nd International Conference on Chemical Looping (2012), 26-28 September, Darmstadt, Germany

[37] Anthony EJ. Solid looping cycles: a new technology for coal conversion. Ind. Eng.Chem.Res, (2008) 47, 1747-1754

[38] Jin H, Ishida M. A new type of coal gas fuelled Chemical Looping Combustion, Fuel (2004) 83, 2411-2417.

[39] Mattisson T, Lyngfelt A, Leion H. Chemical Looping with oxygen uncoupling for combustion of solid fuels, Int J Greenhouse Gas Control (2009) 3, 11-19.

[40] Hoteit A, Forret A, Pelletant W, Roesler J, Gauthier T. Chemical Looping Combustion with different types of liquid fuels, Oil Gas Sci Technol. (2011) 66, 193-199.

[41] Moldenhauer P.; Ryden M.; Mattisson T. Chemical Looping Combustion and Chemical Looping reforming of kerosene in a circulating fluidized-bed 300W laboratory reactor Int J Greenhouse Gas Control (2012) 9, 1-9

[42] Cao Y, Casenas B, and Pan W.P., Investigation of Chemical Looping Combustion by solid fuels. 2. redox reaction kinetics and product characterization with coal, biomass, and solid waste as solid fuels and CuO as an Oxygen carrier, Energy \& Fuels , (2006) 20, 1845-1854

[43] Shen L.,Wu J., Xiao J., Song Q., Xiao R., Chemical Looping Combustion of Biomass in a $10 \mathrm{kWth}$ reactor with iron oxide as an oxygen carrier, Energy \& Fuels (2009), 23, 2498-2505

[44] Rydén M, Lyngfelt A. Using steam reforming to produce hydrogen with carbon dioxide capture by chemical-looping combustion. Int J Hydrogen Energ. (2006), 31,1271-1283.

[45] Ortiz M, Abad A, de Diego LF, García-Labiano F, Gayán P, Adánez J. Optimization of hydrogen production by Chemical Looping auto-thermal Reforming working with Ni-based oxygen carriers. Int J Hyd Energ (2011), 36, 96639672

[46] Fan, L. S., Chemical Looping systems for fossil energy conversions (2010). Wiley: New York, 2010.

[47] Baek, J. I.; Ryu, C. K.; Ryu, J.; Kim, J. W.; Eom, T. H.; Lee, J. B.; Yi, J. Performance Comparison of spray-dried oxygen carriers: the effect of $\mathrm{NiO}$ and pseudoboehmite content in raw materials. Energy \& Fuels (2010), 24, 5757-5764.

[48] Jerndal, E.; Mattisson, T.; Thijs, I.; Snijkers, F.; Lyngfelt, A. NiO particles with Ca and Mg based additives produced by spray-drying as oxygen carriers for Chemical Looping Combustion, Greenhouse Gas control Technologies 9 - GHGT 9, Energy Procedia (2009), 11 479-486.

[49] de Diego L.F., García-Labiano F., Gayán P., Celaya J., Palacios J.M., Adánez J., Operation of a 10 kWth Chemical Looping combustor during 200 h with a CuO-Al2O3 oxygen carrier, Fuel (2007) 86, 1036-1045

[50] Forero Amortegui C.R. , Combustion de gas con captura de CO2 mediante transportadores solidos de oxigeno basados en CuO, PhD thesis, (2011), CSIC Spain

[51] Wei, G.Q.; He, F.; Huang, Z.; Zheng, A.Q.; Zhao, K.; Li, H.B., Continuous operation of a 10 kWth Chemical Looping integrated fluidized bed, Energy \& Fuel (2015), $291233-241$

[52] Linderholm C., Lyngfelt A., Cuadrat A., Jerndal E. , Chemical Looping combustion of solid fuels - Operation in a 10 $\mathrm{kW}$ unit with two fuels, above bed and in bed fuel feed and two oxygen carriers, manganese ore and ilmenite, Fuel (2012) 102, 808-822.

[53] Leion H, Mattissson T., Lyngfelt A., Use of ores and industrial products as oxygen carriers in chemical-looping combustion, Energy \& Fuel (2009), 23, 2307-2315 
[54] Knutsson P., Linderholm C., Characterization of ilmenite used as oxygen carrier in a 100kW chemical-looping combustor for solid fuels, 3rd International conference on Chemical Looping (2014), Göteborg, Sweden , 9-11 September.

[55] Lyngfelt A., Linderholm C., Chemical Looping Combustion of solid fuels - Technology overview and recent operational results in 100 kW Unit, Energy Procedia (2014) 63, 98-112

[56] Lambert A., Comte E., Marti D., Sozinho T., Bertholin S., Stainton H., Yazdanpanah M., On the mechanisms of oxygen carrier degradation during multiple CLC cycles, 6th High Temperature Solid Looping Network Meeting (2013), Milan, 2-3 sept.

[57] Mattisson T., Jardna A., Lyngfelt A. ,Reactivity of some metal oxides supported on alumina with alternating methane and oxygen, application for Chemical Looping Combustion, Energy \& Fuels (2003), 17, 643-651

[58] Iliuta I;, Tahoces R., Patience G.S., Rifflart S., Luck F., Chemical Looping Combustion process: kinetics and mathematical modeling, AIChE Journal (2010) 56, 4

[59] Leion H. , Mattisson T., Lyngfelt A., The use of petroleum coke as fuel in chemical-looping combustion, Fuel (2007) 86, 1947-1958

[60] Ströhle J , Orth M., Epple B., Design and operation of a $1 M_{\text {th }}$ Chemical Looping plant, Applied Energy (2014) 113 1490-1495

[61] Ohlemuller P., J.P.Bush, M.Reitz, J.Strohle, B.Epple, Chemical Looping Combustion of hard coal, authothermal operation of a $1 \mathrm{MW}_{\text {th }}$ Pilot Plant, Journal of Energy Resources Technology, (2016) 138 1-7

[62] Andrus, H., Chui J., Thibeault P., Edberg C., Turek, D., Kenney, J. Abdulally I., Chapman P., Kang S, Alstom's limestone-based (LCLTM) Chemical Looping process; 2nd International Conference on Chemical Looping (2012) TU Darmstadt (Germany), 26 - 28 September.

[63] Ma J., Zhao H., Tian X., Wei Y., Zhang Y., Zheng C., Continuous operation of interconnected fluidized bed reactor for Chemical Looping Combustion of $\mathrm{CH}_{4}$ using hematite as oxygen carrier, Energy \& Fuels (2015), 29, 3257-3267

[64] Bao J., Li Z., Sun H., Cai N., Continuous test of IImenite-based oxygen carriers for Chemical Looping Combustion in a dual fluidized bed reactor system Ind. Eng. Chem. Res. (2013), 52, 14817-14827

[65] Wang S., Wang G., Jiang F., Luo M, Li H.,Chemical Looping combustion of coke oven gas by using Fe2O3/CuO with MgAl2O4 as oxygen carrier, Energy Environ. Sci. (2010), 3, 1353-1360

[66] Li J., Dong C., Zhang J., Yang Y., Experimental research on gas-solid flow in a dual fluidized bed, International conference on sustainable power generation and supply (2009), 1-4, 1834-1839

[67] Bourgeon S., Gauthier T., Guillou F., Stainton H., Chemical Looping Combustion ; development status and perspectives, $2^{\text {nd }}$ International conference on Chemical Looping (2012) TU Darmstadt (Germany), 26 - 28 September

[68] Sit S.P., Reed A., Hohenwarter U., Horn V., Marx K. and Pröll T. 10 MW CLC field pilot, $2^{\text {nd }}$ International conference on Chemical Looping (2012) TU Darmstadt (Germany), 26 - 28 September

[69] Laihong Shen, private communication

[70] Barišić V., E. Coda Zabetta, T. Eriksson, A. Hotta, S. Kokki, K. Nuortimo, J. Palonen, CFB technology provides solutions for reducing $\mathrm{CO}_{2}$ emissions, IFSA (2008), Industrial Fluidization South Africa,.3-23. Edited by T. Hadley and P.Smit, Cradle of Humankind: South Africa Institute of Mining and Metallurgy.

[71] ENCAP public activity report (2009), http://cordis.europa.eu/documents/documentlibrary/123991251EN6.pdf

[72] Guio-Perez D.C, Pröll T., Hofbauer H., Influence of ring type internals on the solids residence time distribution in the fuel reactor of a dual circulating fluidized bed system for Chemical Looping Combustion, Chemical engineering Research and Design, (2014) 92, 1107-1118

[73] Penthor S., Stolhof M., Pröll T., Hofbauer H., Detailled fluid dynamic investigation of a novel fuel reactor concept for Chemical Looping Combustion of solid fuels, Powder Technology (2016) 287, 61-69.

[74] Wells J.W., Process and apparatus for the fluidized catalytic cracking of an hydrocarbon feed, (1998) US Patent 5851380

[75] Thon A., Kramp M., Hartge E.U, Heinrich S. Werther J.,Operational experience with a coupled fluidized bed system for Chemical Looping Combustion of solid fuels, $2^{\text {nd }}$ international conference on Chemical Looping, 2-28 september (2012), Darmstadt, Germany

[76] Yazdanpanah MM, Forret A, Gauthier T, Delebarre A. An experimental investigation of L-valve operation in an interconnected circulating fluidized bed system. Powder Technol (2012) 221, 236-244.

[77] M.M. Yazdanpanah, a. Hoteit, A. Forret, T. Gauthier, A. Delabarre, Gas tracer study in a non-mechanical L-Valve, in "10th International Conference on Circulating Fluidized Beds and Fluidization Technology - CFB-10" (2013) Eds, ECl Symposium Series, Volume RP7.

[78] Knowlton T.M., Hirsan I., L-valves characterized for solids flow, Hydrocarbon Processing (1978) 27, 149-156 
[79] Yang, W-C., Knowlton T.M. L-valves equations. Powder technology (1993) 77, 49-54

[80] Yang W.C. Handbook of fluidization and fluid-particle systems, (2003) CRC Press

[81] Yazdanpanah.M.M. PhD (2011) Investigation of a Chemical Looping Combustion (CLC) Configuration with gas feed, PhD thesis (1991) INPL, Nancy, France

[82] Yazdanpanah M.M., Forret A., Gauthier T., Impact of size and temperature on the hydrodynamics of Chemical Looping Combustion, Applied Energy (2015) 157, 416-421.

[83] Yazdanpanah M.M., Forret A, Gauthier T, Delebarre A., An experimental investigation of loop-seal operation in an interconnected circulating fluidized bed system. Powder Technol. (2013) 237, 266-275.

[84] Abdulally I., Beal C., Andrus H., Apple B., Lyngfelt A., Mani B., Alstom's Chemical Looping Prototypes Program Update, 37th International Technical Conference on Clean Coal \& Fuel Systems (2012), June, Clearwater, L, USA.

[85] Hoteit A., Guillou F, Rifflart S., Gauthier T., Particle separation device for Chemical Looping Combustion loop (2011), Patent WO2011/151537

[86] Werther J., Hartge E.-U., A population balance model of the particle inventory in a fluidized-bed reactor/regenerator system, Powder Technol. (2004) 148 113-122.

[87] Kramp M., Thon A. , Hartge E.-U., Heinrich S., Werther J., The role of attrition and solids recovery in a Chemical Looping Combustion process, Oil Gas Sci. Technol.-Rev. IFP Energies Nouvelles (2011) 66 (2) 277-290.

[88] Amblard B., Bertholin S., Bobin C., Gauthier T., Development of an attrition evaluation method using a jet cup rig. Powder Technol. (2015) 274 455-465.

[89] Cocco R., Arrington Y., Hays R., Findlay J., Karri S.B.R., Knowlton T.M., Jet cup attrition testing, Powder Technol. (2010) $200224-233$.

[90] Bi HT, Ellis N, Abba IA, Grace JR. A state-of-the-art review of gas-solid turbulent fluidization. Chem Eng Sci (2000) 55, 4789-4825.

[91] Foka M, Chaouki J, Guy C, Klvana D., Gas phase hydrodynamics of a gas-solid turbulent fluidized bed reactor, Chem Eng Sci (1996) 51 713-23.

[92] Ellis N., Hydrodynamics of gas-solid turbulent fluidized beds (2003) University of British Colombia (UBC).

[93] Rodrigues S., Flow modeling of Group B particles in the transport regime for CLC, PhD Dissertation (2014) Université Claude Bernard, Lyon 1, France.

[94] Rodrigues S.S., Forret A., Montjovet F., Lance M., Gauthier T., Riser hydrodynamic study with different Group $B$ powders, Powder Technol. 272 (2015) 300-308.

[95] Rodrigues S.S., Forret A., Montjovet F., Lance M., Gauthier T. ,CFD modeling of riser with Group B particles, Powder Technol. (2015) 283 519-529.

\section{List of Symbols}

$\mathrm{G}_{0}: \quad$ L-valve solid flow constant $\left(\mathrm{kg} / \mathrm{s} / \mathrm{m}^{2}\right)$

$\mathrm{G}_{\mathrm{s}}$ : Solid mass flux $\left(\mathrm{kg} / \mathrm{s} / \mathrm{m}^{2}\right)$

k : $\quad$ L-valve constant (-)

$\mathrm{IA}_{20}$ : Attrition index corresponding to the amount of fines below $20 \mu \mathrm{m}$ generated by attrition (\%)

$\mathrm{IA}_{44}$ : Attrition index corresponding to the amount of fines below $44 \mu \mathrm{m}$ generated by attrition (\%)

$R_{0}$ : Oxygen transport capacity of the oxygen carrier (wt.\%)

$\Delta \mathrm{x}$ : Fraction of oxygen transport capacity used for combustion (-)

$U_{H}$ : Actual gas velocity in the horizontal section of the L-Valve $(\mathrm{m} / \mathrm{s})$

$\mathrm{U}_{\mathrm{mf}}$ : Minimum fluiidisation velocity $(\mathrm{m} / \mathrm{s})$

$\mathrm{V}_{\mathrm{sg}}$ : Superficial gas velocity $(\mathrm{m} / \mathrm{s})$ 